\title{
The Uncertainty Channel of Contagion
}

\author{
Prakash Kannan and Fritzi Köhler-Geib
}




\title{
IMF Working Paper
}

\author{
Research Department
}

The Uncertainty Channel of Contagion

\section{Prepared by Prakash Kannan and Fritzi Köhler-Geib *}

Authorized for distribution by Jörg Decressin

2 FUREH 2009

\begin{abstract}
This Working Paper should not be reported as representing the views of the IMF. The views expressed in this Working Paper are those of the author(s) and do not necessarily represent those of the IMF or IMF policy. Working Papers describe research in progress by the author(s) and are published to elicit comments and to further debate.
\end{abstract}

The 2007 subprime crisis in the U.S. triggered a succession of financial crises around the globe, reigniting interest in the contagion phenomenon. Not all crises, however, are contagious. This paper models a new channel of contagion where the degree of anticipation of crises, through its impact on investor uncertainty, determines the occurrence of contagion. Incidences of surprise crises lead investors to doubt the accuracy of their informationgathering technology, which endogenously increases the probability of crises elsewhere. Anticipated crisis, instead, have the opposite effect. Importantly, this channel is empirically shown to have an independent effect beyond other contagion channels.

\section{Author's E-Mail Address:pkannan@imf.org; fkoehler@worldbank.org}

\footnotetext{
* The authors would like to thank Fernando Broner, Antonio Ciccone, Jörg Decressin, Pablo Fleiss, Harald Fadinger, Eduardo Fernandez-Arias, Malte Geib, Michael Grimm, Christian Holzner, Francisco Penaranda, Thijs van Reens, Monika Schnitzer, Jaume Ventura, Joanne Yoong, seminar participants at the University of Munich, University Pompeu Fabra in Barcelona, the International Monetary Fund, the World Bank, as well as participants at the Spring Meeting of Young Economists 2007, and at the IEA and EEA meetings 2008 for their helpful comments and suggestions. Additionally, we would like to thank Gaston Gelos for provision and information regarding part of the data set used in the empirical part of the paper. Fritzi Köhler-Geib thankfully acknowledges financial support by the German Academic Exchange Service (DAAD) and the Kurt Fordan Foundation.
} 


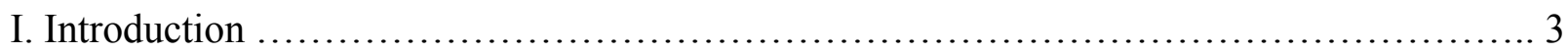

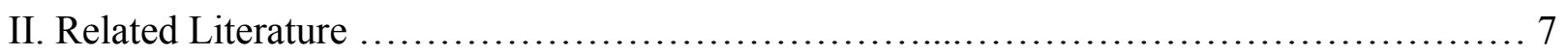

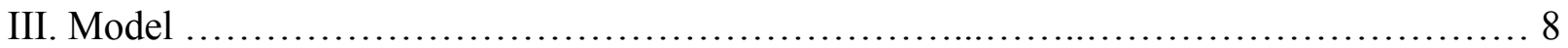

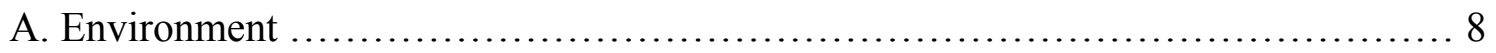

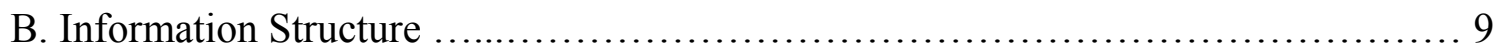

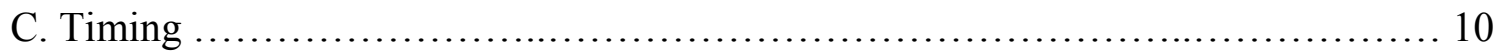

D. Investor's Problem ........................................................ 10

E. Firm's Problem .......................................................... 11

F. Endogenizing the Share of Informed Investors .............................. 13

G. Summary of Model and Testable Hypotheses ............................. 14

IV. Empirical Analysis ............................................................ 16

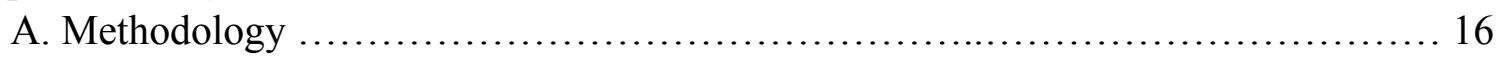

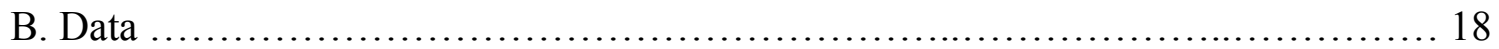

C. Results ............................................................ 19

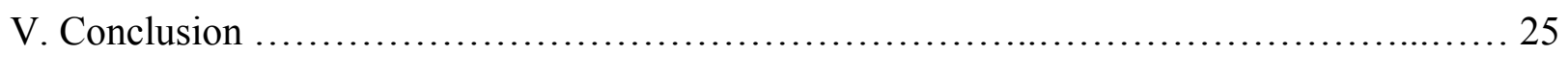

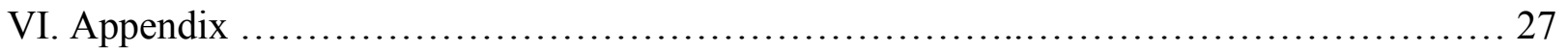

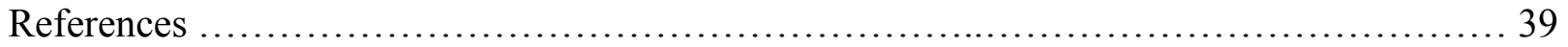

Tables

1. Step 1-Effect of Crisis in "Country $A$ " on Uncertainty in "Country $B$ " ............... 21

2. Step 2-Effect of Uncertainty on Probability of Crisis, all Initial Crisis Countries ......... 23

3. Step 2-Effect of uncertainty on probability of crisis, without any interaction ............. 24

4. Marginal Effect of Uncertainty on the Probablity of a Crisis ......................... 25

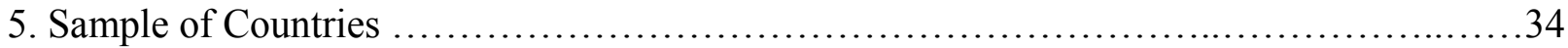

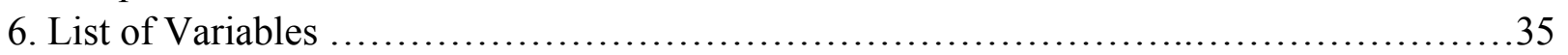

7. Step 2-Effect of Uncertainty on the Probablity of a Crisis, Restricting Attention to the Mexican, Russian and Thai Crises ............................................... 37

8. Step 2-Effect of Uncertainty on the Probablity of a Crisis, Additional Control for Common

Overexposed Fund Investors................................................. 38

Figures

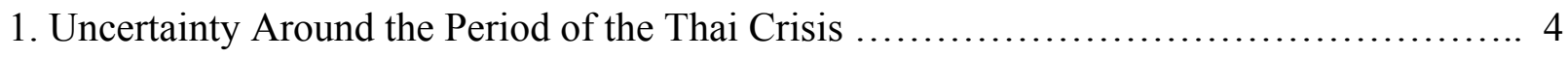

2. Uncertainty Around the Period of the Argentine Crisis.................................5 


\section{INTRODUCTION}

The spread of financial crises, or contagion, has reemerged as a pressing issue following the succession of financial and economic crises around the globe that began with the unraveling of the subprime crisis in the United States in 2007. Prior to these events, emerging market crises that started in Mexico in 1994-95, Thailand in 1997, and Russia in 1998 entailed subsequent crises in neighboring and far-away economies. A similar accumulation of crises occurred in industrialized countries in the context of the European Exchange Rate Mechanism (ERM) crisis in 1992. While these events suggest contagion across countries is at work, several other episodes, such as the crises in Brazil in 1999, Turkey in 2001, and Argentina in 2001-02, primarily remained local. These differential patterns raise the question of why some crises have a contagious effect on other economies while others do not.

Several recent papers have addressed this differential occurrence of contagion. ${ }^{1}$ A common theme arising from this literature is the dependence of contagion on the nature of the crisis in the "initial-crisis" country. In particular, a distinction has been drawn between "surprise crises" - crises that were unexpected by market participants - and "anticipated crises"crises that were largely expected well before they actually occurred. A variety of measures have been used to identify the degree of anticipation. Kaminsky, Reinhart and Vegh (2003) use changes in domestic bond spreads, and revisions to sovereign credit ratings, as a measure of the degree to which markets anticipate a crisis. Didier, Mauro and Schmukler (2006), instead, use net sales or purchases by mutual funds in the period leading up to a crisis. Finally, Rigobon and Wei (2008) and Mondria and Quintana-Domeque (2007) use the number of news articles about a particular country as a measure of anticipation. The consensus arising from these different methodologies is that the earlier crises-Mexico, Thailand and Russia — were largely unanticipated events, while the more recent set of crises - Brazil, Turkey and Argentina - were anticipated. The link between the degree of anticipation and the occurrence of contagion has led some authors to regard the surprise element as a necessary condition for contagion. ${ }^{2}$ The literature thus far, however, has not come up with a satisfying mechanism to explain the differential occurrence of contagion. ${ }^{3}$

\footnotetext{
${ }^{1}$ See, for example, Kaminsky, Reinhart and Vegh (2003), Didier, Mauro and Schmukler (2006) and Rigobon and Wei (2008).

${ }^{2}$ Kaminsky, Reinhart and Vegh (2003), for example, consider it as one of the three necessary elements in their "unholy trinity".

${ }^{3}$ An exception is Mondria (2006) where, in the event of a surprise crisis, investors reallocate their limited attention to the crisis country, which induces them to liquidate positions in other countries. If a crisis was anticipated instead, the investor can take the time necessary to increase her information processing resources, thus reducing the impact of the attention reallocation on other countries.
} 


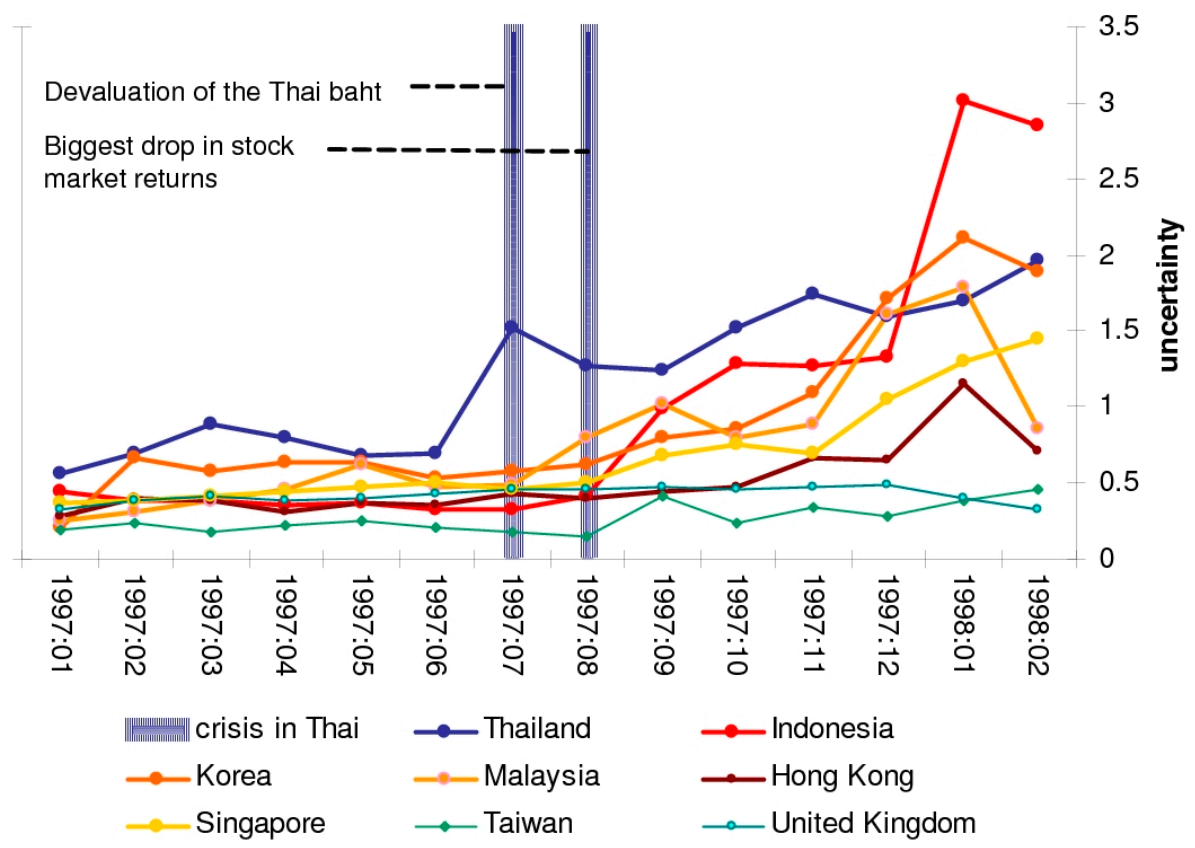

Figure 1: Uncertainty Around the Period of the Thai Crisis

This paper proposes a new channel for the international transmission of crises-the "uncertainty channel of contagion"- that explains the differential pattern of contagion. Stylized facts surrounding the Thai and Argentine crises illustrate the potential relevance of this channel. Figures 1 and 2 show the behavior of the degree of "uncertainty", as measured by the dispersion of GDP forecasts based on surveys of private sector analysts, around the period involving the Thai crisis (a surprise crisis) and the Argentine crisis (an anticipated crisis). The two vertical bars in Figure 1 show the two most pronounced events in the Thai crisis - the severe devaluation of the Baht in the beginning of July 1997 and the substantial drop in stock market returns one month later. ${ }^{4}$ The individual lines show the measure of uncertainty regarding fundamentals for a select group of countries. Following the onset of the Thai crisis, uncertainty regarding fundamentals increased substantially for several neighboring countries. In the case of Korea, the build-up of uncertainty was subsequently followed by a currency and stock market crisis in November of 1997. In contrast, Figure 2 shows the behavior of the uncertainty measure around the Argentinean crisis in 2001. Following the announcement of default in December 2001, uncertainty regarding the fundamentals of neighboring economies barely changed. In fact, as we will see later, the level of uncertainty, conditional on other macroeconomic and financial variables, actually decreased.

\footnotetext{
${ }^{4}$ The dates are chosen in accordance with Kaminsky, Reinhart and Vegh (2003) and Goldstein (1998).
} 


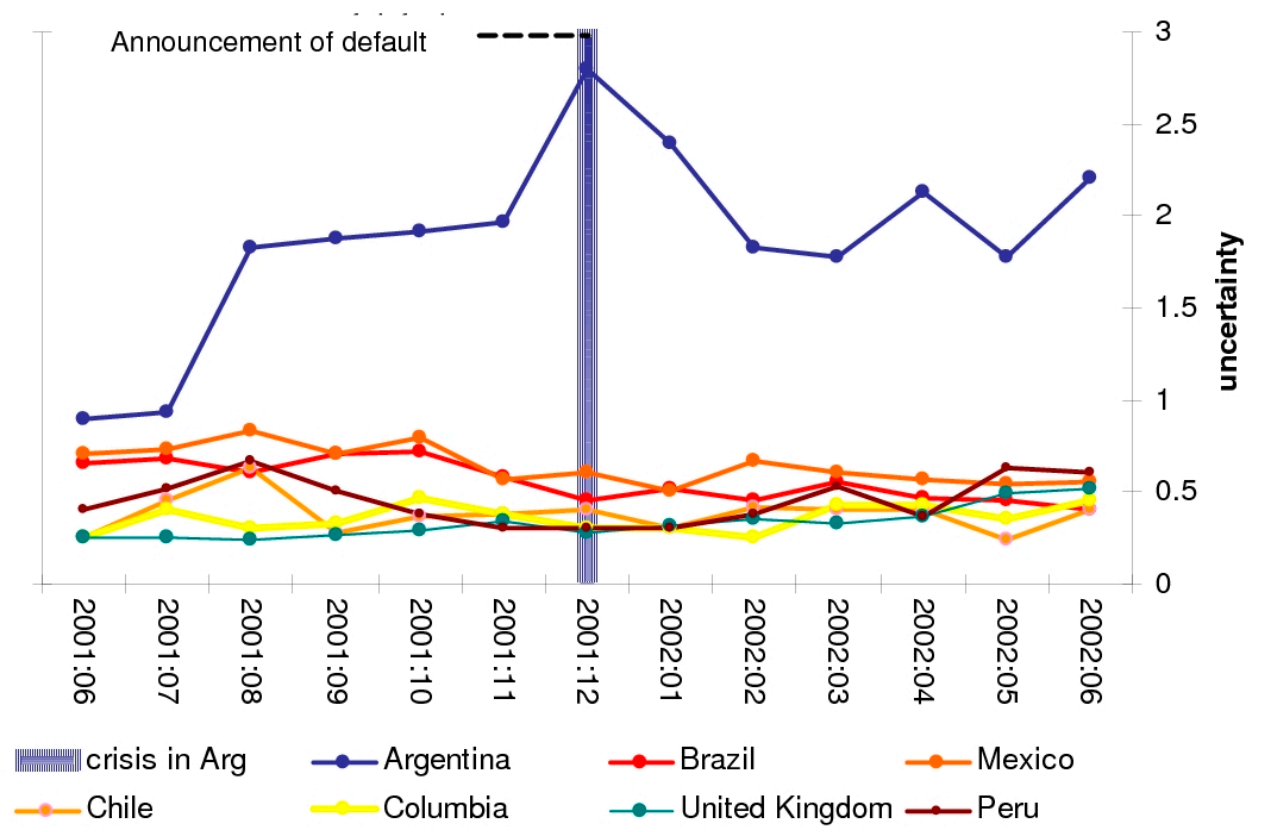

Figure 2: Uncertainty Around the Period of the Argentinean Crisis

In line with these stylized facts, we present a theoretical model and empirical evidence illustrating the differential occurrence of contagion after surprise versus anticipated crises. The basic mechanism behind the model can be summarized as follows: Investors trade securities whose expected return is tied to the fundamentals of the economy in which the issuing firm operates. The spread between the price of the security and its eventual payout is a measure of the funding costs for the firm. Investors, however, are imperfectly informed regarding the state of fundamentals, but can choose to acquire a form of informationgathering technology that improves the precision of their information. The crucial assumption of the model is that investors are unsure as to how precise the informationgathering technology actually is. Instead, they have a belief regarding its precision, which they update by observing developments in other countries. If, for example, a surprise crisis happens in another country, investors will feel less confident about their informationgathering technology, and consequently, ascribe a lower belief regarding its precision. In equilibrium, this change in beliefs will lower the proportion of investors who adopt the information-gathering technology and, hence, increase the aggregate uncertainty regarding fundamentals in the country the investor is invested in. As this uncertainty increases, so do the spreads faced by the firm, which in turn increases the probability of a crisis in the country. In other words, surprise crises in one country lead investors to doubt the accuracy of their information and lead them to rationally make decisions that increase the probability of a crisis in a second country in which they have investments. 
The model, as described above, yields two testable predictions. First, surprise (anticipated) crises result in an increase (decrease) in uncertainty, as measured by the dispersion of beliefs regarding fundamentals, in other countries. Second, an increase in uncertainty is associated with a higher probability of the incidence of a financial crisis. The empirical analysis likewise proceeds in two distinct steps. First, we use fixed-effects panel estimations to establish the link between the crisis in an initial crisis country and uncertainty regarding fundamentals in other countries. Second, we validate the importance of uncertainty by quantifying the effect of an increase in uncertainty on the probability of a crisis in another economy. While the first step is much more crucial to show the empirical relevance of the suggested contagion channel, we run the second step for completeness.

We construct a rich data set comprising 38 countries with monthly data spanning the period from December 1993 to September 2005. The sample of countries, and the associated time frame, enables the inclusion of the following six significant crisis periods into the analysis: Mexico (1994-95), Thailand (1997), Russia (1998), Brazil (1999), Turkey (2001) and Argentina (2001-02). These crises cover both currency crises as well as episodes of sovereign debt default. In both cases, however, these episodes featured significant drops in stock market returns in the respective economies. This measure is also consistent with the setup in the model where a crisis is defined as an episode where firms are forced to abandon ongoing projects, thereby resulting in a collapse of their market value.

The empirical analysis provides strong evidence for the existence, and importance, of the uncertainty channel of contagion. Firstly, we find that the incidence of the Mexican, Thai and Russian crises - identified by the literature to be surprise crises - increase the level of uncertainty regarding fundamentals in other countries. The effect is found to be stronger for countries within the same region. In contrast, we find that anticipated crises, namely the Brazilian, Turkish and Argentine crises, actually decrease the level of uncertainty in other countries, again with a stronger effect in the same region. The importance of changes in the level of uncertainty is captured by our second main finding, which shows that higher uncertainty is associated with a higher probability of the occurrence of a crisis. Most importantly, this effect is significant even after controlling for other channels of contagion that have been proposed in the literature, such as common creditors, trade links, the size effect of the initial stock market, and for overexposed common fund investors. As the marginal analysis shows, the effect is also not negligible in size. The combination of our two main findings confirms our hypotheses that surprise and anticipated crises have different contagion effects based on how they affect the level of investor uncertainty regarding fundamentals.

The rest of the paper is organized as follows: In Section II, we relate the current paper to the existing literature on contagion. Following that, in sections III and IV, we describe the model and the results from the empirical analysis. Finally, Section V contains the conclusion. 


\section{RELATED LiterATURE}

The literature on contagion covers important contributions on both theoretical and empirical fronts. Therefore, a significant challenge for this paper is to show that uncertainty has a significant effect on the propagation of crises over-and-above other channels that have already been explored. While early research focused on trade linkages and macroeconomic similarities between economies, more recent analyses have emphasized the role of common investors - either through banks, (as in Van Rijckeghem and Weder, 2001; Kaminsky and Reinhart, 2000; and Caramazza, Ricci and Salgado, 2004), or mutual funds, (as in Broner, Gelos and Reinhart, 2006; and Borensztein and Gelos 2000). ${ }^{5}$ Theoretical advances regarding the different propagation mechanisms behind this channel, meanwhile, have examined herding due to fixed information costs (Calvo and Mendoza, 2000), differentially-informed investors (Kodres and Pritsker, 2002), and wealth effects (Goldstein and Pauzner, 2004).

While the model in the present paper has some parallels with the existing literature, it contributes a new mechanism that explains the differential contagion patterns after surprise versus anticipated crises. In the model, contagion occurs through the shift of a threshold equilibrium induced by an increase in the variance of investors' private signals. In this sense, the model features the same implications as those that arise in global game models, such as presented in Morris and Shin (2003). These models, however, do not easily lend themselves to accommodate notions of surprise versus anticipated crises, which we show to be a key element in determining whether contagion happens or not. The model presented in this paper also shares some similarities with Kodres and Pritsker (2002). As is the case in the present paper, their model builds on the imperfect information, rational expectations model of Grossman and Stiglitz (1980). The channel of contagion, however, is fundamentally different. In Kodres and Pritsker (2002), contagion occurs through portfolio rebalancing due to shared macroeconomic risks, keeping the share of informed investors constant. In contrast, the channel of contagion in the present paper relies on an endogenous shift in this very share. The nature of this shift allows for a differential pattern of contagion depending on whether the crisis is anticipated or not, a feature that is not present in Kodres and Pritsker (2002).

To the best of our knowledge, there has not been an attempt to quantify the role of uncertainty in the context of contagion. In this sense the present paper fills a gap. However, the impact of uncertainty on currency crises has been the subject of several recent papers. Prati and Sbracia (2002) and Bannier (2006) study the impact of greater dispersion of GDP forecasts on the Asian and Mexican crises respectively, focussing on the time-series dimension of the data. Tillman (2004), instead, uses the difference between the price of closed-end equity funds and their underlying net asset values as a measure of the

\footnotetext{
${ }^{5}$ For the literature on trade linkages see, for example, Gerlach and Smets (1996) and Glick and Rose (1999). For macroeconomic similarities, see, for example, Goldstein (1998).
} 
heterogeneity of information to study the role of information disparities in the ERM crisis. In addition to having a different motivation, the empirical analysis in our paper also differs substantially in a variety of ways. Firstly, by applying panel estimation techniques we additionally exploit the cross sectional dimension of the data, which seems most appropriate given the static nature of the underlying theoretical models in this branch of the literature. Secondly, the data set spans a longer time horizon allowing us to consider more than just one crisis episode. Thirdly, by focusing on sharp falls in stock markets, we also capture more than just currency crises, which is the focus of all the studies mentioned above.

\section{MODEL}

The following model illustrates the mechanisms behind the uncertainty channel of contagion. The model focuses on sharp drops in stock prices, which tend to be concurrent with a broad range of financial crises. The hypotheses derived from the model are then empirically validated in the next section.

\section{A. Environment}

The model features two countries, which we label as $A$ and $B$, and two types of agents: a representative firm and foreign investors. We assume that there are two groups of foreign investors, each a continuum of measure one, that invest exclusively in country $A$ and country $B$, respectively. Time is discrete and divided into two periods: $t=1,2$. The "fundamentals" of an economy can be summarized by a single parameter, $\theta_{\mathrm{c}}$, where $c \quad\{A, B\}$. Following Angeletos and Werning (2006), we assume that the unconditional distribution of $\theta$ is the improper uniform over the entire real line.

The representative firm in each economy has an ongoing project, which requires funding each period. The firm faces two forms of uncertainty. The first is related to the rate of return on its projects, which is tied to the level of fundamentals. The rate of return is given by a function $R(\theta) \quad C^{2}$ where $R^{\prime}>0, R^{\prime \prime}>0$ and $R(0)=0$. The second form of uncertainty that the firm faces is a private, unobserved, liquidity shock, $S_{c}$, which we assume is drawn from a standard normal distribution: $S_{c} \sim N(0,1)$ and $c \quad\{A, B\}$. In response to the liquidity shock, the firm issues (or redeems) securities that are claims on the residual value of the project. We assume for simplicity that the residual value per share is given by the level of fundamentals, $\theta$. The securities are issued at the beginning of the period and the payoff is delivered at the end of the period. The firm also has access to a risk-free rate of return, which we normalize to zero.

Investors have preferences that take the form of the constant absolute risk aversion utility function

$$
U(W)=-\mathrm{e}^{-\gamma W}
$$

where $W$ is end of period wealth and $\gamma$ is the coefficient of absolute risk aversion. 


\section{B. Information Structure}

The level of the fundamentals of an economy is not revealed perfectly to an investor. Instead, the investor only receives a signal on the fundamentals. The investor, however, can invest in a form of information-gathering technology, at a cost $c$, that improves the precision of her signal. One could think of $c$ as the cost of setting up a research department, for example. We will label investors who decide to acquire the information-gathering technology as "informed" (with subscript $I$ ) and investors who don't as "uninformed" (with subscript $U$ ). As we will see later, having two different groups of investors, informed versus uninformed, is an intuitive way to motivate the increase in the actual variance of forecasts. ${ }^{6}$ Investors only receive signals related to the fundamentals of the country in which they are investing in. Furthermore, we assume that both groups of investors have access to the same informationgathering technology. ${ }^{7}$

The informed investor receives a signal, $x_{I, i}=\theta_{\mathrm{c}}+\varepsilon_{I, i}$ where $\varepsilon_{I, i} \sim N\left(0, \sigma_{\mathrm{I}}^{2}\right)$. The uninformed investor instead receives a signal, $x_{U, i}=\theta_{\mathrm{c}}+\varepsilon_{U, i}$ where $\varepsilon_{U, i} \sim N\left(0, \sigma_{\mathrm{U}}^{2}\right)$. We will find it more convenient to refer to the precisions of the signals, which are respectively denoted as $\alpha_{I}=$ $1 / \sigma_{I}^{2}$ and $\alpha_{U}=1 / \sigma_{U}^{2}$. The stochastic variables, $\varepsilon_{I, i}, \varepsilon_{U, i}$ and $S_{c}$, are assumed to be independent of each other. As mentioned earlier, the information-gathering technology has a higher signal precision, i.e., $\alpha_{I}>\alpha_{U}$. To simplify the discussion in the rest of this section, we assume $\alpha_{U}=1$.

We introduce a behavioral element to this fairly standard setup. Investors are assumed to be unsure about the actual precision of the technology. They have, however, a common prior: $\hat{a}_{I}>\alpha_{U}$. Investors judge the precision of the information-gathering technology by its ability to predict "crises". If a crisis that is anticipated by the market materializes, investors become more confident about the technology and have posterior beliefs, $\hat{\alpha}_{I}^{G}>\hat{\alpha}_{I}$. If an anticipated crisis does not occur, or if a surprise crisis occurs, investors become less confident in the technology and have posterior beliefs, $\hat{\alpha}_{I}^{B}$ where $\alpha_{U}<\hat{\alpha}_{I}^{B}<\hat{\alpha}_{I}$. Note that, unlike the bias inherent in self-attribution theories (see Bem, 1965, or Daniel, Hirshleifer and Subrahmanyam, 1998), we allow for investors to adjust their priors both ways following the observation of a public signal. One could think of the downward adjustment of the posterior belief after a non-materialized anticipated crises in terms of an investment bank starting to mistrust its research department that issues crises warnings without ever a crisis happening. Later on, we will define precisely what the terms "anticipated" and "surprise crises" mean within the context of this model. The measure of informed investors (which will be later endogenously determined) is $\lambda$. The measure of uninformed investors is therefore $(1-\lambda)$.

\footnotetext{
${ }^{6}$ If instead there were only one group of investors, contagion could only occur if the actual variance of forecasts were exogenously shifted in a differential manner depending on the nature of the initial crisis.

${ }^{7}$ Such an extreme assumption is not necessary. All we need is for investors to gain some knowledge regarding their own technology by observing what happens in other countries.
} 


\section{Timing}

The two periods in the model are set up such that all the events concerning country $A$ occur in period 1, while all events concerning country $B$ occur in period 2 . In our empirical analysis in the next section, we will refer to country $A$ as the "initial crisis" country. The timing of events in period 1 is as follows:

1. Investors decide whether or not to invest in the information-gathering technology.

2. Investors receive their individual signals on $\theta_{A}$ and purchase (or short) the securities issued by the firm.

3. Based on the realized values of the fundamentals and their liquidity shock, the firm decides whether to continue its project or not.

Events in the second period follow the same ordering with the exception that investors update their priors on the reliability of the information-gathering technology following the events in Country $A$.

\section{Investor's Problem}

An individual investor solves the following problem:

subject to

$$
\max E\left(U\left(W_{i}\right)\right)=E\left(-e^{-\gamma W_{i}}\right)
$$

$$
W_{i}=W_{0, i}-P_{c} k_{j, i} \dashv \theta_{c} k_{j, i}-I_{j=I} \cdot c
$$

where $W_{0, i}$ is initial wealth, $P_{c}$ and $\theta_{c}$ are respectively the price and the payoff of the security issued by the firm in a given country, and $k_{j, i}$ is the quantity demanded by investor $i$. The subscript $j \quad\{I, U\}$ refers to whether the investor is informed or uninformed. If she chooses to be informed $\left(I_{j=I}=1\right)$, then she pays $c$ to obtain the technology.

As in much of the literature, we will restrict ourselves to linear price functions. Since the supply of assets is uncertain and unobserved, the price realization serves as a signal that, conditional on the realization of the fundamentals, is normally distributed (since $S_{c}$ is normal). The equilibrium price function that results from the investors' maximization problem is as follows (see Appendix for derivation):

$$
P_{c}=\theta_{c}-\frac{\gamma}{\lambda \hat{\alpha}_{I}+(1-\lambda)} S_{c}
$$

Equation (3) is the price of the security issued by the firm in country $c$, which has a level of fundamentals represented by $\theta_{c}$ and faces a liquidity shock of size $S_{c}$. $\left(\theta_{c}-P_{c}\right)$ is the discount with which the security is priced relative to its fundamental value. While the expected value of the discount is zero, the realized value will be positive if the security is in positive supply. 
Two parameters that determine the size of the discount are the coeffecient of absolute risk aversion, $\gamma$, and the beliefs on the precision of the information-gathering technology. Higher levels of risk aversion and lower beliefs on the precision result in a higher discount for the security and thus a higher cost of funds for the firm. When the investor is more risk averse or has lower beliefs on the precision of her information, she will act less aggressively with respect to her signal and, consequently, demand less assets for any given deviation of her signal and the price. As a result, the price becomes less informative as an aggregator of information which results in a greater dispersion between the price of the security and its fundamental value. If instead we had perfect information, $\hat{a}_{I}-\propto$, the equilibrium price will be exactly equal to the payout of the bond, $\theta_{c}$. It is important to note that the liquidity shock is unobservable. If instead it were public information, prices would be fully informative about the level of the fundamentals, rendering the decision to be informed versus uninformed irrelevant.

\section{E. Firm's Problem}

The firm has an ongoing project which yields $R(\theta)$ for every unit invested. Regardless of the liquidity shock, the firm will abandon the project if the rate of return on the project is lower than the risk-free rate of return, $R(\theta)<0$. Given the functional form assumptions for $R($.$) , this$ condition is equivalent to $\theta<0$. In the event of a liquidity shock, the firm borrows funds from investors by issuing securities that are claims on the residual value of the project. $^{8}$ Based on the results in the last section, the firm in a given country will be able to raise $P_{c}\left(\theta_{c}, S_{c}\right)$ per share that it issues. The firm will now continue the project if the return from investing the funds that it raises, $P_{c} S_{c}$, is greater than its residual value, $\theta_{c} S_{c}$ :

$$
R\left(\theta_{c}\right) P_{c}\left(\theta_{c}, S_{c}\right) S_{c}>\theta_{c} S_{c}
$$

The following proposition shows the existence of a cutoff value of $\theta_{c}, \theta_{c}^{*}$, below which the project will be abandoned. This cutoff value is a function of the degree of investors' risk aversion, $\gamma$, the size of the liquidity shock, $S_{c}$, the beliefs on the precision of information, $\hat{a}_{I}$, and the proportion of informed investors, $\lambda$. The relationship of $\theta^{*}{ }_{c}$ with these parameters is stated in the Corollary to Proposition 1.

Proposition 1: For a given realization of a positive liquidity shock, there exists a threshold value of fundamentals, $\theta_{c}^{*}\left(\gamma, S_{c}, \hat{a}_{I}\right)>0$, implicitly defined by

$$
R\left(\theta_{c}^{*}\right) P_{c}\left(\theta_{c}^{*}, S_{c}\right)=\theta_{c}^{*}
$$

such that the firm will choose to discontinue its project if $\theta_{c}<\theta_{c}^{*}\left(\gamma, S_{c}, \hat{Q}_{I}\right)$.

\footnotetext{
${ }^{8}$ We interpret negative realizations of the liquidity shock as cases where the firm has excess liquidity resulting in a negative net supply of the security. In this case, the firm will maintain the same criterion for the continuation of the project as in the case where there are no liquidity shocks.
} 
Corollary 1: Based on the equation that defines $\theta_{c}^{*}$, equation (5), we have that the threshold value for fundamentals

(i) increases if investors are more risk-averse, $\frac{\partial \theta_{c}^{*}}{\partial \gamma}>0$.

(ii) is higher for higher realizations of the liquidity shock, $\frac{\partial \theta_{c}^{*}}{\partial S_{c}}>0$.

(iii) is lower for higher beliefs on the precision of the information-gathering technology, $\frac{\partial \theta_{c}^{*}}{\partial \hat{\alpha}_{I}}<0$.

(iv) is lower for a higher proportion of informed investors, $\frac{\partial \theta_{c}^{*}}{\partial \lambda}<0$.

A higher threshold value for the level of fundamentals implies a higher conditional likelihood, from the viewpoint of investors, that the firm will discontinue its project. The results in the Corollary to Proposition 1 show that the firm is more likely to abandon its project if investors are more risk-averse, if it faces larger liquidity shocks and, more importantly for the purposes of this paper, if the variance of beliefs regarding the level of fundamentals increases.

The discontinuation of a project will result in a loss of value for the firm from the expected stream of returns from the project. We interpret this sharp loss of value as a crisis episode. While, in reality, firms are terminating and starting projects on an ongoing basis, the use of the term "crisis" in this case is justified as we have a representative firm in our model. The discontinuation of a project for the firm in the model, therefore, would translate to a drop in the stock market index for the country. We will be using this definition of a crisis in our empirical analysis.

We can now be more precise about the definition of an anticipated or surprise crisis, within the framework presented in this model. Recall that investors in country $B$ do not get any private signals regarding the fundamentals in country $A$. They do, however, observe the price of the security, $P_{A}$. As we have seen in the discussion of investor behavior, prices in this model serve as an aggregator of information, albeit an imprecise one. The "market's" expectation of the level of fundamentals can therefore be summarized by the expected value of $\theta_{A}$ conditional on the price of the firm's security: $\mathrm{E}\left[\theta_{A} \mid P_{A}\right]$.

As mentioned earlier, investors are assumed to update their common priors on the precision of the information-gathering technology based on its ability to predict crises. Based on the information available to investors, we can say that a crisis is anticipated if either $\mathrm{E}\left[\theta_{A} \mid P_{A}\right]<$ 0 , which is the case where the rate of return on the project is lower than the risk-free rate, or $\mathrm{E}\left[P_{A} R\left(\theta_{A}\right)-\theta_{A} \mid P_{A}, S_{A}>0\right]<0$, which is the case where the net rate of return on the project is negative given that the firm faces a positive liquidity shock. Since all investors share a 
common information set, they will have a common posterior belief on the precision of the information-gathering technology based on whether an anticipated crisis materializes or not.

\section{F. Endogenizing the Share of Informed Investors}

The linkages between the behavior of investors and firms in this model make crises endogenous. For a given positive realization of the liquidity shock for the firm and a given level of fundamentals, lower beliefs by investors regarding the precision of forecasts make it more likely that the firm will abandon its project, thus resulting in a crisis.

Unfortunately, we do not observe investors' beliefs on the precision of the forecasts. Instead, we only observe the actual variance of forecasts, which does not depend on beliefs of investors, but rather on the true variance of the process. Since we assume that the noise terms for the informed and uninformed signals are uncorrelated, we have that the variance of forecasts, conditional on $\theta$, is

$$
V(\text { forecast } \mid \theta)=\lambda^{2} \sigma_{I}^{2}+(1-\lambda)^{2} \sigma_{U}^{2}
$$

As indicated by equation (6), the observed variance of forecasts changes with the proportion of informed versus uninformed investors. In order to explain changes in the observed variance of forecasts, we now endogenize the investors decision to acquire the informationgathering technology.

The decision to acquire the information-gathering technology is done prior to the beginning of each period and prior to the realization of any of the random variables. Since all agents are ex-ante identical, all investors will decide to acquire the investment technology if $E U_{I}>E U_{U}$, where $E U_{I}$ is the expected utility of the informed and $E U_{U}$ is the expected utility of the uninformed. Likewise, no one will acquire the technology if the opposite inequality holds. An interior solution, $\lambda \quad(0,1)$, will be obtained only when we have $E U_{I}=E U_{U}$. The following proposition shows us how the share of informed investors is determined in equilibrium.

Proposition 2: The share of informed investors, $\lambda$, in equilibrium will be as follows:

$$
\begin{aligned}
& \lambda=0 \text { if } c>b \\
& \lambda=1 \text { if } c<a ; \text { and } \\
& \lambda \quad(0,1) \text { if } c \quad[a, b] .
\end{aligned}
$$

where $a=\frac{1}{2 \gamma} \ln \left(\frac{\hat{\alpha}_{I}\left(\gamma^{2}+\hat{\alpha}_{I}\right)}{\gamma^{2}+\hat{\alpha}_{I}^{2}}\right)$ and $b=\frac{1}{2 \gamma} \ln \left(\hat{\alpha}_{I}\right)$.

The share of informed investors in equilibrium depends on the cost of acquiring the information-gathering technology, $c$. If the cost of acquiring the technology is too large or too small, we will have either all investors choosing not to acquire the technology or all of 
them choosing to be informed. For intermediate values of $c$, however, we will have an interior value for the share of informed investors. The boundary values are functions of the risk aversion parameter and the beliefs on the precision of the information technology. Low levels of risk aversion and high beliefs on the signal's precision lead to a wider interval for interior solutions. We then have the following Corollary:

Corollary 2: Let the cost of acquiring information-gathering technology be such that we have an interior solution for $\lambda$. We then have that the fraction of informed investors increases for higher beliefs of the precision of the information-gathering technology, $\frac{\partial \lambda}{\partial \hat{\alpha}_{I}}>0$, for beliefs $\hat{a}_{I}$ that are not too large.

As investors' beliefs regarding the precision of the information-gathering technology increases, Corollary 2 states that the share of informed investors increases. The shift in the extensive margin of informed investors will then change the observed variance as noted by equation (12). The qualifier "for beliefs $\hat{o}_{I}$ that are not too large", however, is necessary due to the information content embedded in prices. As in Grossman and Stiglitz (1980) and Diamond and Verrecchia (1981), the informativeness of prices in this model has a paradoxical implication in that the more informative prices are, the less incentives there are for individual agents to acquire information, which in turn makes prices less informative. So, if investors' beliefs regarding the precision of the information-gathering technology are too high, then any further increase will reduce the share of investors who choose to acquire the technology since they can rely on the information content in prices instead. The effect of higher beliefs regarding the precision of the information-gathering technology on the share of informed investors is, therefore, ultimately an empirical question. We will verify this hypothesis in the empirical section.

\section{G. Summary of Model and Testable Hypotheses}

In summary, the various elements of the model illustrate the different contagion effects of an anticipated versus a surprise financial crisis. If a surprise crisis occurs, investors attribute a lower level of precision to their information-gathering technology, which leads to a smaller share of investors adopting the technology (Corollary 2). The resulting higher variance of forecasts endogenously increases the probability of a crisis (Corollary 1 (iii) and (iv)).

The intuition behind the result is as follows: When faced with a noisier signal, investors behave less aggressively with respect to the information content of their signal. As a result, investors purchase (or short) fewer securities for a given divergence between the price of the security and what they expect the payout to be. This makes the price a noisier signal on fundamentals. From the perspective of the firm, this increases the wedge between the price that they obtain per security and the payout that they need to make. In other words, their cost of funds increases making the termination of a project more likely. 
Based on the results in this section, we have two testable hypotheses, which we take up in turn in the next section:

Hypothesis 1: An anticipated (surprise) crisis in Country A results in an decrease (increase) in the variance of forecasts regarding the fundamentals in Country $B$.

Hypothesis 2: An increase (decrease) in the variance of forecasts results in a higher (lower) probability of a crisis in Country $B$.

There are several elements of the model that merit some discussion. Firstly, the use of distinct groups on investors, at a first glance, seems to contradict the increasing evidence that common investors have been at the heart of recent episodes of contagion. The goal of this paper, however, is to show that uncertainty regarding fundamentals is a distinctly different channel of contagion from the other channels that have been explored. While the use of separate investors was primarily to simplify certain aspects of the model, it serves to underscore our point that the uncertainty channel of contagion does not require the group of investors to be the same across countries. What is crucial instead is that investors gain some knowledge regarding the precision of their information signals by observing what happens in other countries.

The model has also abstracted from most of the other contagion channels, such as trade links or other macroeconomic factors, by assuming that the fundamentals are independent. However, one can imagine extensions of this model to cases where the fundamentals are correlated, say through a common regional shock. A common investor, in this case, could then be receiving signals of this regional shock and update her beliefs regarding the precision of this signal based on whether a surprise or anticipated crisis happens somewhere else in the region. A surprise crisis then will lead the investor to lower her beliefs regarding the precision of her signal, with similar consequent effects as in the current model. In fact, we find evidence of such a regional response in our empirical analysis, suggesting that such an extension may be worth pursuing for future research.

Finally, as our model has implications for the optimality of public disclosure of information, it is worth contrasting our model with that of Morris and Shin (2002). In their model, a coordination element between agents results in situations where the public release of information can reduce welfare. There are no coordination problems in our model and, therefore, better public information, insofar as it improves the precision of investor forecasts, is welfare improving. 


\section{EMPIRICAL ANALYSIS}

In this section, we subject the two hypotheses derived from the model to empirical analysis. An important aspect of the empirical analysis is the verification of a separate and nonnegligible effect of uncertainty on the spread of crises beyond other channels of contagion that have already received attention in the literature. In what follows, we first describe the estimation methodology followed by a description of the data set. We then report the main results along with some analysis of robustness.

\section{A. Methodology}

The empirical strategy is designed as a two-step procedure: In the first step, we estimate the effect of the crisis in an initial crisis country, labeled $A$, on uncertainty in another country, labeled $B$. In doing so, we control for other potential domestic and external drivers of uncertainty. In the second step, we analyze the effect of uncertainty regarding fundamentals in countries $B$ on the probability of a crisis there. In this second step, we control for alternative contagion channels, such as trade links, common creditors, and over-exposed fund investors. Additionally, we control for domestic and external drivers of crises.

\section{Estimating the effect of the initial crisis on uncertainty}

In the first step of our empirical analysis, we estimate the effect of the crisis in Country $A$ on uncertainty in Country $B$ employing fixed effects panel regressions. For this purpose we specify the following test:

$$
\begin{aligned}
U N C_{B, t}= & \alpha_{0}+\alpha_{1} C R_{A r g, t-1}+\ldots+\alpha_{6} C R_{T u r, t-1}+\alpha_{7} C R_{B, t-1}+\alpha_{8} Z_{B, t-1}+\alpha_{9} I N T_{t-1} \\
& +\delta_{B}+\varepsilon_{B, t}
\end{aligned}
$$

where $U N C_{B, t}$ signifies the level of uncertainty in a country $B$ at time $t$, and $C R_{A, t-1}$ captures crisis dummies for countries $A$. This set of initial crisis countries consists of Argentina, Brazil, Mexico, Russia, Thailand, and Turkey, commonly identified as initial crises countries in the literature. ${ }^{9}$ We exclude these six countries from the group of countries, $B$. The other variables in the regression are control variables: $C R_{B, t-1}$ represents a dummy of crisis incidences in Country $B$ itself, $Z_{B, t-1}$ represents other potential domestic drivers of uncertainty, such as the mean of growth expectations, stock market volatility, and proxies for economic, financial and political risks while $I N T_{t}$ represents the interest rate in advanced economies which has shown to have a strong impact on capital flows into and out of emerging markets (see Fernandez-Arias, 1996). $\delta_{B}$ captures country fixed effects. The level of uncertainty varies significantly across countries, pointing to systematic differences

\footnotetext{
${ }^{9}$ See sources cited in the Introduction.
} 
between countries that necessitate the control for country effects. Finally, $\varepsilon_{B, t}$ captures the error term.

\section{Estimating the effect of uncertainty on the probability of a crisis}

In the second step of our empirical analysis, we measure the effect of uncertainty on the probability of a crisis. For this purpose, we run two sets of discrete-dependent variable regressions. First, we specify the following test:

$$
\begin{gathered}
\operatorname{Pr}\left(C R_{B}=1 \mid X \beta\right)=G\left\{\beta_{0}+\beta_{1} \sum_{A \in\{\operatorname{Arg}, \ldots, \text { Tur }\}} C T G_{A, B, t-1} * C R_{A, t-1}+\beta_{2} U N C_{B, t-1} * \sum_{A \in\{A r g, \ldots, T u r\}} C R_{A, t-1}\right. \\
\left.\dashv \beta_{3} Z_{B, t-1} \dashv \beta_{4} I N T_{t-1} \dashv \delta_{B} \dashv \boldsymbol{1}_{B, t}\right\}
\end{gathered}
$$

where $G($.$) represents the standard normal and the logistic cumulative distribution functions,$ respectively, in the probit and logit estimations we run. The conditioning vector $X$ refers to all the right-hand-side variables. $C T G_{A, B, t-1}$ represents the set of control variables for alternative channels of contagion from Country $A$ to Country $B$. We control for almost all other channels that have been highlighted in previous research: common creditors, trade links, dependence on a common overexposed fund investors, and the market size of the crisis country. These control variables are interacted with the crisis dummy for the initial-crisis countries, which are the same set of countries used in the first step of our analysis.

Additionally, $Z_{B, t-1}$ represents a set of potential domestic drivers of crises, such as the lag of mean of growth expectations and the lag of stock market volatility. As before, $I N T_{t-1}$ represents the interest rate in advanced economies, and $\delta_{B}$ country effects.

The coefficient of interest here is $\beta_{2}$, which captures the effect of uncertainty regarding fundamentals on the probability of a crisis. The use of the interaction term, however, carries the risk that the coefficient simply picks up the direct effect of the crises in $A$ rather than the effect of uncertainty. To ensure that this is not the case, we estimate a separate set of regressions where we enter the uncertainty variable and the initial crises variables separately:

$$
\begin{aligned}
\operatorname{Pr}\left(C R_{B}=1 \mid X \beta\right)=G & \left\{\beta_{0}+\beta_{1} C R_{A, t-1}+\ldots+\beta_{6} C R_{A, t-1}+\beta_{7} U N C_{B, t-1}+\beta_{8} Z_{B, t-1}\right. \\
& \left.+\delta_{B}+\eta_{B, t}\right\}
\end{aligned}
$$

The variables have the same interpretation as before. For robustness, we run the same sets of regressions assuming a logistic distribution. In addition, we estimate a linear probability model to overcome the potential incidental-parameter problem. 


\section{B. Data}

We build a rich data set comprising monthly observations from December 1993 to September 2005. The sample comprises 38 countries - 15 developed and 23 emerging - where the selection of the period and countries reflects availability of data. The set of countries is listed in Table 5 in the Appendix.

The explanatory variable that is of interest in the current analysis is uncertainty regarding fundamentals. Based on our model, uncertainty is defined as the variance of private signals around the true value of the fundamentals that affect the rate of return on investments. Such data, however, is not directly observable. Since the return on investment typically correlates strongly with the growth rate of output, we follow Prati and Sbracia (2002) and use the standard deviation of GDP growth forecasts from Consensus Economics as a reasonable proxy..$^{10}$

To match our empirical analysis with the model presented earlier, we define a crisis as an episode that features a sharp drop in stock returns. Monthly stock market returns, computed from the International Finance Corporation (IFC) investable US dollar total return index, serve as a basis for this crisis dummy. We use nominal US dollar returns because we are interested in the optimization problem of a foreign investor. ${ }^{11}$ When needed, we complement the returns with data from Morgan Stanley Capital International (MSCI) or national sources. ${ }^{12}$ With these data on stock market returns, we construct a binary crisis variable in which a month is counted as a crisis month if the total return undershoots its sample mean by more than two standard deviations. After this initial drop, the subsequent months are also counted as crisis months until returns revert to the one standard deviation band around the sample mean.

As noted in the previous sections, we use a rich set of domestic control variables. The mean of growth forecasts, obtained from Consensus Economics, is used to control for the state of the economy, while the volatility of stock market returns is used to disentangle the effect of uncertainty regarding fundamentals from general high variability in the domestic market. Additionally, we use indices of financial, economic, and political risk computed by the

\footnotetext{
${ }^{10}$ See Table 6 in the Appendix for a description of the exact construction of the variable. In the main analysis, we use a weighted average of current and following year forecasts as described in Table 6 . However, as a robustness check we repeat all estimations using only current year forecasts, and only following-year forecasts, separately. The results are qualitatively the same and quantitatively similar.

${ }^{11}$ The investable indices take into consideration restrictions on foreign investment. Therefore, this measure represents the part of the national stock markets accessible to foreign investors, which is relevant in the context of contagion.

${ }^{12}$ For more details, please refer, to Table 6 in the Appendix.
} 
International Country Risk Guide (ICRG) to control for potential domestic reasons for changes in uncertainty. In the context of contagion, these indicators were first used by Broner, Gelos, and Reinhart (2006) .

Following Fernandez-Arias (1996) and the extensive literature on "push" and "pull" factors of capital flows into and out of emerging markets, we use the interest rate on 10-year US government bonds to control for interest rates in advanced economies, an important external driver of investment decisions in emerging markets.

The key set of control variables that we include relate to alternative channels of contagion. A variety of alternative contagion channels appear to be relevant in the context of stock market drops. Firstly, we control for contagion through common creditors. In line with Van Rijckeghem and Weder (2001), we use consolidated data of BIS banking statistics to construct an index of contagion through the presence of a common creditor. However, we construct a different index from theirs. The index used in this paper reflects the dependence on common creditors as opposed to their measure, which reflects competition for funds. In the context of stock market drops, the dependence on common investors appears more relevant than competition for their funding. ${ }^{13}$ Another relevant channel of contagion is trade linkages with the crisis country. Following Glick and Rose (1999), we use bilateral export data from the IMF Direction of Trade Statistics to construct the measure of trade links. However, in contrast to their measure, we use the share of exports to Country $A$ relative to Country $B$ 's total exports. Finally, we also control for the possibility of contagion through common overexposed fund investments, using the index developed by Broner, Gelos and Reinhart (2006).

\section{Results}

We now discuss the estimation results of equations (7) to (9). Our findings suggest that the uncertainty channel of contagion does indeed play a role in spreading crises across economies. First, we find a significant and robust effect of the initial crisis on uncertainty in other countries in the direction predicted by the model — surprise crises increase uncertainty in other countries while anticipated crises have the opposite effect. Second, we find a significant and robust effect of uncertainty on the probability of a crisis. Importantly, we find that the effect is robust to the inclusion of various alternative channels of contagion.

\section{Effect of a crisis on uncertainty in other countries}

Table 1 summarizes the results of the fixed-effects panel regressions, equation (7), with the different columns corresponding to different subsamples and estimation techniques. The

\footnotetext{
${ }^{13}$ For details on the construction of this index, please refer to Table 6 in the Appendix.
} 
analysis of the effect of an initial crisis on uncertainty regarding fundamentals in other countries shows an interesting pattern: We find that the Mexican, Russian, and Thai crisesidentified as surprise crises in the literature - significantly increase uncertainty regarding fundamentals in other countries. However, in the case of the three other crises, the Brazilian, Turkish, and Argentine crises - identified as anticipated crises in the literature - the panel analysis shows a different pattern: The Turkish and Argentine crises significantly decrease the level of uncertainty in potentially-affected countries. These results are robust to the choice of regional or emerging markets sub-samples and the inclusion of a large number of control variables. The effect of the Brazilian crisis is less clear.

Some interesting results emerge from a closer look at the coefficients on the surprise crises. Surprise crises prompt stronger effects on uncertainty in emerging markets than in all countries. This finding might reflect higher costs of information gathering in emerging markets that are on average less transparent than advanced economies. ${ }^{14}$ This could explain a higher disincentive to investors to bear the cost of acquiring information about emerging markets if surprised by a crisis. The estimations also show strong positive effects of surprise crises within their own region. Of the three surprise crises, the Thai crisis had the strongest impact on uncertainty in other countries. Viewed through the lens of the model, this observation suggests that the Thai crisis shattered the confidence in information-gathering technology more than the other two surprise crises. The coefficients for anticipated crises display a similar pattern, with a stronger impact in emerging markets. While the incidences of the Argentine and Turkish crises resulted in a stronger decrease in the standard deviation of growth forecasts in the emerging market sub-sample than in all countries, the effect of the Brazilian crisis is not clear. In the regressions it turns out insignificant.

The coefficients on the control variables used in the regressions have the expected signs. In particular, as expected, the US bond yield has a positive and strongly significant effect on the uncertainty around the world, with a stronger effect in emerging markets. Also, as expected, the lag of the mean of growth expectations affects uncertainty negatively. This variable can be interpreted as a summary of the state of the fundamentals together with investors' expectations about it. If the fundamentals are good - or everyone expects them to be goodthen disagreement about the fundamentals decreases. The lag of the crises in the potentiallyaffected countries shows a positive and significant effect on uncertainty. Past stock market volatility also has a strong positive and significant effect on uncertainty. Additionally, we use the financial, economic, and political risk indices from ICRG as a summary of risk factors in the economy, influencing the level of uncertainty. The coefficients on these variables are mostly not significant in the regressions.

\footnotetext{
${ }^{14}$ See Gelos and Wei (2005) for a thorough discussion of the role of transparency in investment decisions of emerging market mutual funds.
} 


\section{Table 1: Step 1 - Effect of Crisis in "Country $A$ " on Uncertainty in "Country $B$ "}

Fixed effects panel regressions of uncertainty on the lag of crisis in initial crises countries

Step 1, Effect of crises in the initial crises countries, A, on the uncertainty in potentially affected countries, B.

Uncertainty in country B at $\mathrm{t}$ is the dependent variable. Countries A are excluded from the group of other countries, B.

(3)

(4)

(5) regional

(6)

\begin{tabular}{|c|c|c|c|c|c|c|c|}
\hline & $\begin{array}{c}\text { all crises, } \\
\text { all } \\
\text { countries }\end{array}$ & $\begin{array}{c}\text { all crises, } \\
\text { emerging } \\
\text { markets }\end{array}$ & $\begin{array}{c}\text { regional } \\
\text { crises, asia } \\
\end{array}$ & $\begin{array}{c}\text { regional } \\
\text { crises, } \\
\text { emerging } \\
\text { asia } \\
\end{array}$ & $\begin{array}{c}\text { regional } \\
\text { crises, } \\
\text { emerging } \\
\text { asia + } \\
\text { turkey } \\
\end{array}$ & $\begin{array}{l}\text { regional } \\
\text { crises, } \\
\text { eastern } \\
\text { europe } \\
\end{array}$ & $\begin{array}{c}\text { regional } \\
\text { crises, latin } \\
\text { america } \\
\end{array}$ \\
\hline lag of crisis in Argentina & $\begin{array}{l}-0.018^{*} \\
(0.010)\end{array}$ & $\begin{array}{l}-0.032^{*} \\
(0.018)\end{array}$ & & & & & $\begin{array}{l}-0.115^{* * * *} \\
(0.041)\end{array}$ \\
\hline lag of crisis in Brazil & $\begin{array}{c}0.003 \\
(0.013)\end{array}$ & $\begin{array}{c}0.027 \\
(0.025)\end{array}$ & & & & & $\begin{array}{c}0.013 \\
(0.052)\end{array}$ \\
\hline lag of crisis in Mexico & $\begin{array}{l}0.029 * \\
(0.017)\end{array}$ & $\begin{array}{c}0.036 \\
(0.032)\end{array}$ & & & & & $\begin{array}{l}0.109 * \\
(0.063)\end{array}$ \\
\hline lag of crisis in Russia & $\begin{array}{c}0.045^{* * *} \\
(0.010)\end{array}$ & $\begin{array}{c}0.080^{* * *} * \\
(0.018)\end{array}$ & & & & $\begin{array}{c}0.145^{*} * * \\
(0.031)\end{array}$ & \\
\hline lag of crisis in Thailand & $\begin{array}{c}0.063^{*} * k^{*} \\
(0.009)\end{array}$ & $\begin{array}{c}0.083^{* * *} \\
(0.016)\end{array}$ & $\begin{array}{l}0.101^{*} \text { 水水 } \\
(0.016)\end{array}$ & $\begin{array}{c}0.106^{*} * * \\
(0.024)\end{array}$ & $\begin{array}{c}0.104 * * * \\
(0.023)\end{array}$ & & \\
\hline lag of crisis in Turkey & $\begin{array}{c}-0.020^{* * *} \\
(0.009)\end{array}$ & $\begin{array}{c}-0.046^{* * * *} \\
(0.017)\end{array}$ & & & $\begin{array}{c}-0.068^{* * * *} \\
(0.026)\end{array}$ & $\begin{array}{l}-0.027 \\
(0.027)\end{array}$ & \\
\hline lag of 10 year US gov bond rate & $\begin{array}{l}2.582^{* * * *} \\
(0.517)\end{array}$ & $\begin{array}{l}2.987^{* * * *} \\
(1.007)\end{array}$ & $\begin{array}{l}5.228 * * * \\
(0.825)\end{array}$ & $\begin{array}{l}4.660^{* * * *} \\
(1.253)\end{array}$ & $\begin{array}{l}3.226^{* * *} \\
(1.361)\end{array}$ & $\begin{array}{l}3.255^{*} \\
(1.708)\end{array}$ & $\begin{array}{l}6.328^{* * * *} \\
(1.875)\end{array}$ \\
\hline lag of crisis in country B & $0.159^{* * * *}$ & $\begin{array}{l}0.131^{* * * *} \\
(0.024)\end{array}$ & $\begin{array}{l}0.234 * * * * \\
(0.028)\end{array}$ & $0.232^{* * * *}$ & $\begin{array}{l}0.234 * * * \\
(0.035)\end{array}$ & $\begin{array}{l}0.070^{*} \\
(0.036)\end{array}$ & $\begin{array}{l}0.163^{* * *} * \\
(0.054)\end{array}$ \\
\hline lag of mean growth expectations & $\begin{array}{c}-0.121^{*} \text { * } \\
(0.002)\end{array}$ & $\begin{array}{c}-0.124^{*} * k^{2} \\
(0.003)\end{array}$ & $-0.134 * * *$ & $\begin{array}{c}-0.133^{*} \text { * }{ }^{2} * \\
(0.006)\end{array}$ & $\begin{array}{c}-0.132^{*} * k^{2} \\
(0.006)\end{array}$ & $\begin{array}{c}-0.100 * * * \\
(0.008)\end{array}$ & $\begin{array}{c}-0.108^{*} * k^{*} \\
(0.009)\end{array}$ \\
\hline lag of stock market volatility & $\begin{array}{c}5.161 * * 3 \\
(0.349)\end{array}$ & $\begin{array}{c}5.454 * * * \\
(0.481)\end{array}$ & $\begin{array}{c}4.652^{*} \text { * } \\
(0.679)\end{array}$ & $\begin{array}{c}5.167 * * \\
(0.846)\end{array}$ & $\begin{array}{c}4.982^{* * *} \\
(0.845)\end{array}$ & $\begin{array}{c}3.900^{*} * \\
(0.721)\end{array}$ & $\begin{array}{c}5.972^{*} * * \\
(1.333)\end{array}$ \\
\hline lag of economic risk index & $\begin{array}{l}-0.001 \\
(0.004)\end{array}$ & $\begin{array}{c}0.001 \\
(0.005)\end{array}$ & $\begin{array}{l}-0.002 \\
(0.006)\end{array}$ & $\begin{array}{l}-0.005 \\
(0.007)\end{array}$ & $\begin{array}{l}-0.005 \\
(0.007)\end{array}$ & $\begin{array}{l}-0.003 \\
(0.013)\end{array}$ & $\begin{array}{l}0.019^{*} \\
(0.011)\end{array}$ \\
\hline lag of financial risk index & $-0.007 * *$ & $-0.013 * *$ & $\begin{array}{l}-0.009 \\
(0.006)\end{array}$ & $\begin{array}{c}-0.008 \\
(0.008)\end{array}$ & $\begin{array}{l}-0.009 \\
(0.008)\end{array}$ & $\begin{array}{l}-0.006 \\
(0.010)\end{array}$ & $\begin{array}{l}-0.022 * \\
(0.013)\end{array}$ \\
\hline lag of political risk index & $\begin{array}{l}-0.004 \\
(0.003)\end{array}$ & $\begin{array}{l}-0.002 \\
(0.005)\end{array}$ & $\begin{array}{l}-0.013^{* *} \\
(0.005)\end{array}$ & $\begin{array}{c}-0.019^{* * * *} * \\
(0.007)\end{array}$ & $\begin{array}{l}-0.018^{* * *} \\
(0.007)\end{array}$ & $\begin{array}{l}-0.001 \\
(0.010)\end{array}$ & $\begin{array}{l}0.009 \\
(0.008)\end{array}$ \\
\hline Constant & $\begin{array}{c}0.703^{* * *} * \\
(0.032)\end{array}$ & $\begin{array}{c}0.938 * * * \\
(0.059)\end{array}$ & $\begin{array}{l}0.840^{* * * *} \\
(0.045)\end{array}$ & $\begin{array}{l}1.032^{* * * *} \\
(0.065)\end{array}$ & $\begin{array}{c}1.129 * * * \\
(0.074)\end{array}$ & $\begin{array}{c}0.667^{* * *} * \\
(0.100)\end{array}$ & $\begin{array}{l}0.677^{*} * * \\
(0.116)\end{array}$ \\
\hline Observations & 2855 & 1391 & 1142 & 696 & 696 & 353 & 342 \\
\hline Number of country & 32 & 17 & (11." & ? & 7 & 6 & (3)." \\
\hline R-squared & 0.59 & 0.64 & 0.68 & 0.72 & 0.73 & 0.46 & 0.48 \\
\hline
\end{tabular}

To summarize the findings of the first step of our analysis: The analysis shows that surprise crises, such as the Mexican, Russian, and Thai crises, significantly increased our measure of uncertainty in other countries. Meanwhile, anticipated crises, such as the Argentine, Turkish, and Brazilian crises, decreased uncertainty in other countries. These findings are in line with the hypotheses derived from the theoretical model. 


\section{Effect of increased uncertainty on the probability of a crisis}

In the second step of the analysis, we show that increased uncertainty regarding fundamentals increases the probability of a crisis in a country. We begin by running a pooled probit regression of the incidence of a crisis in a country on the interaction of uncertainty in that country with the incidence of an initial crisis, controlling for a set of other factors, as specified in equation (8). Apart from the controls for country effects and the U.S. long-term interest rate in financial centers, the control variables can be classified into two categories: (i) alternative contagion channels, which could influence the likelihood of a crisis in the potentially-affected countries, and (ii) domestic control variables.

Table 2 displays the results of this regression. The first two columns of Table 2 show that the uncertainty variable has a positive and strongly significant effect on the probability of a crisis in a particular country. Column (2) shows that the effect is stronger in emerging economies, once again possibly reflecting the greater degree of information asymmetry in these economies. As a robustness test we also run logit regressions. While column (3) shows that the positive effect of uncertainty on the probability of a crisis is not significant at conventional levels in the set of all countries, column (4) shows that the effect is positive and significant for emerging markets when assuming a logistic distribution. Introducing the dummies into the pooled probit and logit regressions does not seem to create a severe incidental parameter problem, as is apparent from the results using the linear probability model in columns (5) and (6). The magnitude of the effect is smaller, but the effect is still strongly significant and not negligible. These results continue to hold when we only consider the set of surprise crises, which were found to increase the level of uncertainty in other countries (see Table 6 in the Appendix).

With regard to alternative contagion channels, the following variables are controlled for: the common creditor channel of contagion, the direct trade channel, contagion from important stock markets, and contagion through common overexposed fund investors. If not controlling for overexposed common fund investors, we find that common creditors and trade shares have a high explanatory power for the occurrence of a crises in the potentially-affected countries (see Tables 2 and 7). However, when we additionally control for overexposed common fund investors, these two variables become insignificant (see Table 8 in the Appendix). At least in the emerging market sample for which we can control for the overexposure channel, the common creditors and trade share channels do not appear entirely robust. ${ }^{15}$ The domestic control variables - mean growth expectations and stock market

\footnotetext{
${ }^{15}$ We include the channel through overexposed fund investors in separate regressions due to the fact that the index of overexposed common creditors only covers the sample of emerging markets, excluding Ukraine. We are very thankful to Gaston Gelos for making the overexposure index available to us. Due to the expensive underlying source data, we would not have been able to control for this relevant contagion channel otherwise.
} 


\section{Table 2: Step 2 - Effect of Uncertainty on Probability of Crisis, all Initial Crisis Countries}

Discrete dependent variable regressions of crises in potentially affected countries on the lagged uncertainty there Step 2, Effect of uncertainty in potentially affected countries, B, on the occurrence of crises there. A dummy of stock market crises is the dependent variable. Countries A are excluded from the group of other countries, B.

(1)

(2)

(3)

(4)

(5)

(6)

pooled probit,

pooled logit, linear probability,

pooled probit, all crises,

pooled logit, all crises,

probability,

all crises,

all crises, al

emerging

all crises, al

emerging all crises, all emerging

countries

markets

lag of interaction of uncert. in B \&

all initial crises

$0.085^{*}$

$0.104 * *$

markets countries markets

\begin{tabular}{|c|c|c|c|c|c|c|}
\hline $\begin{array}{l}\text { lag of interact. com creditors \& } \\
\text { crisis in A }\end{array}$ & $\begin{array}{c}12.868 * * * \\
(2.809)\end{array}$ & $\begin{array}{c}13.762 * * * \\
(3.124)\end{array}$ & $\begin{array}{c}26.069 * * * \\
(5.570)\end{array}$ & $\begin{array}{c}27.410^{* * *} * \\
(5.892)\end{array}$ & $\begin{array}{c}0.193 * * * \\
(0.063)\end{array}$ & $\begin{array}{c}3.116^{* * *} \\
(0.484)\end{array}$ \\
\hline $\begin{array}{l}\text { lag of interact. tradeshare \& crisis } \\
\text { in A }\end{array}$ & $\begin{array}{c}6.561^{* * *} \\
(2.270)\end{array}$ & $\begin{array}{l}6.446^{* * *} \\
(2.323)\end{array}$ & $\begin{array}{c}13.032 * * * \\
(4.521)\end{array}$ & $\begin{array}{c}12.903 * * * \\
(4.592)\end{array}$ & $\begin{array}{l}1.430 * * * \\
(0.209)\end{array}$ & $\begin{array}{l}1.113 * * * \\
(0.316)\end{array}$ \\
\hline $\begin{array}{l}\text { lag of interact. market size \& crisis } \\
\text { in A }\end{array}$ & $\begin{array}{l}-0.000 \\
(0.000)\end{array}$ & $\begin{array}{l}-0.000 \\
(0.000)\end{array}$ & $\begin{array}{l}-0.000 \\
(0.000)\end{array}$ & $\begin{array}{l}-0.000^{*} \\
(0.000)\end{array}$ & $\begin{array}{c}0.000 \\
(0.000)\end{array}$ & $\begin{array}{c}-0.000^{* *} \\
(0.000)\end{array}$ \\
\hline lag of mean growth expectation & $\begin{array}{l}-0.010 \\
(0.030)\end{array}$ & $\begin{array}{l}-0.016 \\
(0.031)\end{array}$ & $\begin{array}{l}-0.015 \\
(0.059)\end{array}$ & $\begin{array}{l}-0.024 \\
(0.062)\end{array}$ & $\begin{array}{c}0.001 \\
(0.003)\end{array}$ & $\begin{array}{l}-0.001 \\
(0.004)\end{array}$ \\
\hline lag of stockmarket volatiltiy & $\begin{array}{c}0.611 \\
(0.823)\end{array}$ & $\begin{array}{c}0.488 \\
(0.884)\end{array}$ & $\begin{array}{l}1.137 \\
(1.420)\end{array}$ & $\begin{array}{c}0.918 \\
(1.542)\end{array}$ & $\begin{array}{c}0.057 \\
(0.090)\end{array}$ & $\begin{array}{l}0.040 \\
(0.117)\end{array}$ \\
\hline lag of 10 year US gov bond rate & $\begin{array}{l}34.737 * * * \\
(7.272)\end{array}$ & $\begin{array}{c}38.092 * * * \\
(8.220)\end{array}$ & $\begin{array}{c}67.306 * * * \\
(14.390)\end{array}$ & $\begin{array}{l}69.358 * * * \\
(15.654)\end{array}$ & $\begin{array}{l}1.500 * * * \\
(0.437)\end{array}$ & $\begin{array}{c}3.050 * * * \\
(0.820)\end{array}$ \\
\hline country effects & yes & yes & yes & yes & yes & yes \\
\hline Constant & $\begin{array}{c}-4.466 * * * \\
(0.546)\end{array}$ & $\begin{array}{c}-4.599 * * * \\
(0.590)\end{array}$ & $\begin{array}{c}-8.788^{* * * *} \\
(1.125)\end{array}$ & $\begin{array}{c}-8.785^{* * *} \\
(1.177)\end{array}$ & $\begin{array}{c}-0.077 * * \\
(0.031)\end{array}$ & $\begin{array}{c}-0.170^{* * * *} \\
(0.051)\end{array}$ \\
\hline Observations & 1983 & 1280 & 1983 & 1280 & 2989 & 1474 \\
\hline R-squared & & & & & 0.20 & 0.23 \\
\hline
\end{tabular}

volatility - appear with the correct sign, though they turn out to be insignificant. Consistent with the findings in the literature on capital flows, we find a strong and positive relationship between the probablity of a stock market crisis and US long-term interest rates.

Finally, as previously explained, care must be taken to ensure that we are not merely picking up the direct effect of the crises in the initial-crises countries, rather than the effect of uncertainty, when interacting the level of uncertainty in $B$ with the crises in the initial-crises countries. Table 3 shows the result of the regression where the uncertainty variable and the initial crisis variable enter separately. Even here, we find that uncertainty has a distinctly positive, and significant effect, on a crisis event in the same economy.

How important is the effect of uncertainty on the probability of a crisis? Table 4 shows the estimated marginal effects based on the various specifications. After conditioning on the incidence of crises in the initial-crisis countries, the US long-term interest rate and domestic variables, a 1 percent increase in the measure of uncertainty is associated with a 1.8 percent increase in the probability of a stock market crisis in that country. The impact is much higher 


\section{Table 3: Step 2 - Effect of Uncertainty on Probability of Crisis, Without any Interaction}

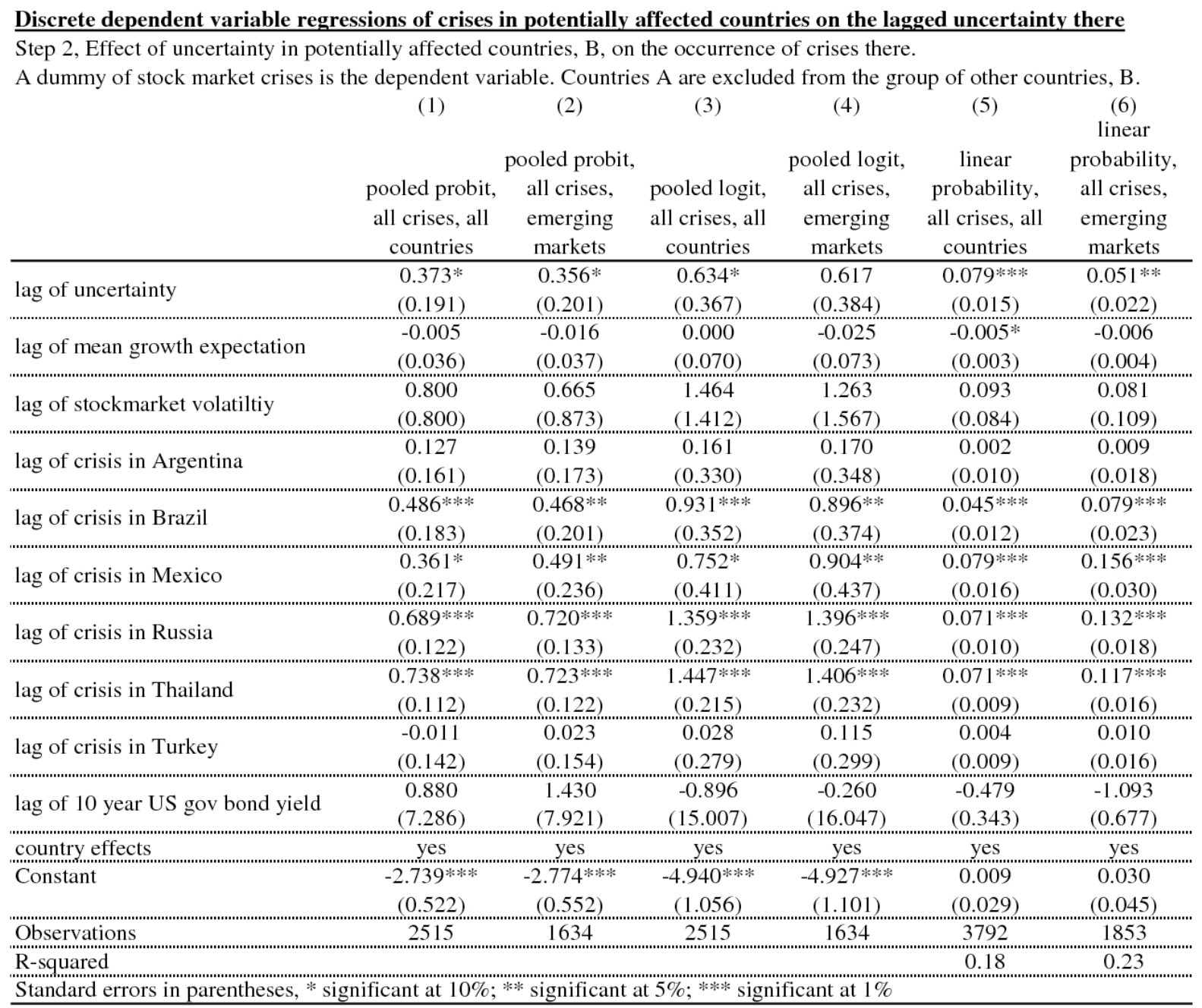

in the case of emerging markets. While this effect might appear small, its relevance becomes apparent when comparing it to the unconditional stock market crisis probability of 4.5 percent in the entire sample and 6.8 percent in the emerging market sample.

Together with the findings in the previous section, the results in the current section support the theoretical model and validate the existence of the uncertainty channel of contagion. Uncertainty regarding fundamentals in a country increases with the occurrence of a surprise crisis in another country. The uncertainty, in turn, leads to an increase in the probability of a crisis. Conversely, in the case of an anticipated crisis in the first country, uncertainty in the second country is reduced, thereby decreasing the probability of a crisis in the second country. Calculating marginal effects makes clear that the effect of the uncertainty on the probability of crises in the potentially-affected countries is not negligible. 


\section{Table 4: Marginal Effect of Uncertainty on the Probability of a Crisis}

Marginal effects of discrete dependet variable regressions

Step 2, Effect of uncertainty in potentially affected countries, B, on the occurrence of crises there.

A dummy of stock market crises is the dependent variable. Countries A are excluded from the group of other countries, B.

\begin{tabular}{|c|c|c|c|c|c|c|c|c|}
\hline & $\begin{array}{c}\text { (1) } \\
\text { pooled } \\
\text { probit, all } \\
\text { crises, all } \\
\text { countries }\end{array}$ & $\begin{array}{l}(2) \\
\text { pooled } \\
\text { probit, all } \\
\text { crises, } \\
\text { emerging } \\
\text { markets }\end{array}$ & $\begin{array}{c}\text { pooled } \\
\text { logit, all } \\
\text { crises, all } \\
\text { countries }\end{array}$ & $\begin{array}{l}\text { (4) } \\
\text { pooled } \\
\text { logit, all } \\
\text { crises, } \\
\text { emerging } \\
\text { markets }\end{array}$ & $\begin{array}{l}\text { (5) } \\
\text { pooled } \\
\text { probit, all } \\
\text { crises, all } \\
\text { countries }\end{array}$ & $\begin{array}{l}\text { (6) } \\
\text { pooled } \\
\text { probit, all } \\
\text { crises, } \\
\text { emerging } \\
\text { markets }\end{array}$ & $\begin{array}{c}(7) \\
\text { pooled } \\
\text { logit, all } \\
\text { crises, all } \\
\text { countries }\end{array}$ & $\begin{array}{c}(8) \\
\text { pooled } \\
\text { logit, all } \\
\text { crises, } \\
\text { emerging } \\
\text { markets }\end{array}$ \\
\hline lag of uncertainty & $\begin{array}{l}0.018^{*} \\
(0.010)\end{array}$ & $\begin{array}{l}0.032 * \\
(0.018)\end{array}$ & $\begin{array}{l}0.635^{*} \\
(0.367)\end{array}$ & $\begin{array}{c}0.615 \\
(0.384)\end{array}$ & & & & \\
\hline $\begin{array}{l}\text { lag of interaction of uncert. in } \\
\text { B \& all initial crises }\end{array}$ & & & & & $\begin{array}{l}0.006^{*} \\
(0.003)\end{array}$ & $\begin{array}{l}0.011^{* *} \\
(0.005)\end{array}$ & $\begin{array}{c}0.126 \\
(0.086)\end{array}$ & $\begin{array}{l}0.166^{*} \\
(0.093)\end{array}$ \\
\hline lag of crisis in Argentina & $\begin{array}{c}0.007 \\
(0.009)\end{array}$ & $\begin{array}{c}0.014 \\
(0.018)\end{array}$ & $\begin{array}{c}0.161 \\
(0.330)\end{array}$ & $\begin{array}{c}0.171 \\
(0.347)\end{array}$ & & & & \\
\hline lag of crisis in Brazil & $\begin{array}{r}0.035^{*} \\
(0.019) \\
0\end{array}$ & $\begin{array}{l}0.059^{*} \\
(0.032)\end{array}$ & $\begin{array}{c}0.925 * * * \\
(0.352)\end{array}$ & $\begin{array}{l}0.904 * * \\
(0.374)\end{array}$ & & & & \\
\hline lag of crisis in Mexico & $\begin{array}{c}0.025 \\
(0.019) \\
0\end{array}$ & $\begin{array}{c}0.063 \\
(0.041)\end{array}$ & $\begin{array}{l}0.755^{*} \\
(0.406)\end{array}$ & $\begin{array}{l}0.897 * * \\
(0.431)\end{array}$ & & & & \\
\hline lag of crisis in Russia & $\begin{array}{c}0.056^{* * *} \\
(0.015)\end{array}$ & $\begin{array}{c}0.100^{* * *} \\
(0.026)\end{array}$ & $\begin{array}{c}1.360^{* * * *} \\
(0.232)\end{array}$ & $\begin{array}{c}1.394 * * * \cdots \\
(0.246)\end{array}$ & & & & \\
\hline lag of crisis in Thailand & $\begin{array}{c}0.062 * * * \\
(0.014)\end{array}$ & $\begin{array}{c}0.100 * * * \\
(0.023)\end{array}$ & $\begin{array}{c}1.448^{* * *} \\
(0.211)\end{array}$ & $\begin{array}{c}1.404 * * * \cdots \\
(0.229)\end{array}$ & & & & \\
\hline lag of crisis in Turkey & $\begin{array}{l}-0.001 \\
(0.007)\end{array}$ & $\begin{array}{c}0.003 \\
(0.015)\end{array}$ & $\begin{array}{c}0.023 \\
(0.286)\end{array}$ & $\begin{array}{c}0.119 \\
(0.306)\end{array}$ & & & & \\
\hline $\begin{array}{l}\text { lag of interact. com creditors \& } \\
\text { crisis in A }\end{array}$ & & & & & $\begin{array}{c}0.906^{*} * * \\
(0.217)\end{array}$ & $\begin{array}{c}1.435^{*} * * * \\
(0.343)\end{array}$ & $26.069^{*} * *$ & $\begin{array}{l}27.410^{* * * *} \\
(5.892)\end{array}$ \\
\hline $\begin{array}{l}\text { lag of interact. tradeshare \& } \\
\text { crisis in A }\end{array}$ & & & & & $\begin{array}{c}0.462^{* * *} \\
(0.163)\end{array}$ & $\begin{array}{c}0.672^{* * *} \\
(0.240)\end{array}$ & $\begin{array}{l}13.032 * * * ' \\
(4.521)\end{array}$ & $12.903 * * *$ \\
\hline $\begin{array}{l}\text { lag of interact. market size \& } \\
\text { crisis in A }\end{array}$ & & & & & $\begin{array}{l}-0.000 \\
(0.000)\end{array}$ & $\begin{array}{l}-0.000 \\
(0.000)\end{array}$ & $\begin{array}{l}-0.000 \\
(0.000)\end{array}$ & $\begin{array}{l}-0.000^{*} \\
(0.000)\end{array}$ \\
\hline lag of mean growth expectation & $\begin{array}{l}-0.000 \\
(0.002)\end{array}$ & $\begin{array}{l}-0.002 \\
(0.003)\end{array}$ & $\begin{array}{c}0.001 \\
(0.070)\end{array}$ & $\begin{array}{l}-0.026 \\
(0.073)\end{array}$ & $\begin{array}{l}-0.001 \\
(0.002)\end{array}$ & $\begin{array}{l}-0.002 \\
(0.003)\end{array}$ & $\begin{array}{l}-0.015 \\
(0.059)\end{array}$ & $\begin{array}{l}-0.024 \\
(0.062)\end{array}$ \\
\hline lag of stockmarket volatiltiy & $\begin{array}{c}0.039 \\
(0.039)\end{array}$ & $\begin{array}{l}0.061 \\
(0.080)\end{array}$ & $\begin{array}{c}1.459 \\
(1.410)\end{array}$ & $\begin{array}{c}1.271 \\
(1.567)\end{array}$ & $\begin{array}{c}0.043 \\
(0.058)\end{array}$ & $\begin{array}{c}0.051 \\
(0.092)\end{array}$ & $\begin{array}{c}1.137 \\
(1.420)\end{array}$ & $\begin{array}{c}0.918 \\
(1.542)\end{array}$ \\
\hline lag of 10 year US gov bond rate & $\begin{array}{c}0.026 \\
(0.363) \\
0 . . .\end{array}$ & $\begin{array}{c}0.204 \\
(0.735) \\
0 . .7\end{array}$ & $\begin{array}{c}-1.536 \\
(15.435)\end{array}$ & $\begin{array}{c}0.571 \\
(16.509)\end{array}$ & $\begin{array}{c}2.446 * * * \\
(0.500)\end{array}$ & $\begin{array}{c}3.972 * * * \\
(0.818)\end{array}$ & $\begin{array}{c}67.306^{* * * *} \\
(14.390)\end{array}$ & $\begin{array}{c}69.358 * * * \\
(15.654)\end{array}$ \\
\hline country effects & yes & yes & yes & yes & yes & yes & yes & yes \\
\hline Constant & & & $\begin{array}{c}-4.908 * * * \\
(1.074)\end{array}$ & $\begin{array}{c}-4.967 * * * \\
(1.125)\end{array}$ & & & $\begin{array}{c}-8.788^{* * *} \\
(1.125)\end{array}$ & $\begin{array}{c}-8.785^{* * *} * \\
(1.177)\end{array}$ \\
\hline Observations & 2515 & 1634 & 2515 & 1634 & 1983 & 1280 & 1983 & 1280 \\
\hline
\end{tabular}

\section{Conclusion}

The global financial crisis that started in the subprime mortgage market in the U.S. has reinforced the notion that contagion is a recurring feature of financial crises in both emerging and advanced economies. The transmission of crises across borders has significant welfare implications and, as such, an understanding of the underlying mechanism is of paramount importance. This paper contributes to this understanding by examining the role of uncertainty in the occurrence of contagion. This topic has not received much attention, especially on the empirical front. The channel fleshed out in this paper can rationalize why contagion sometimes occurs, but sometimes does not. After observing a surprise crisis, investors begin 
to doubt the accuracy of their information, which endogenously increases the probability of a crisis occurring in another country. We call the transmission of crises across countries due to the increased uncertainty regarding the fundamentals of the economy the "uncertainty channel of contagion".

The empirical analysis presents strong evidence which shows that uncertainty-defined as the variance of investor beliefs - plays a distinct and important role in explaining patterns of contagion. The effect of uncertainty remains significant even after controlling for other prominent channels of contagion, such as trade links, overexposed fund investors, and common creditors.

The immediate policy implication that arises from this paper is that surveillance activities have to be an important element in any effort to promote international financial stability. Apart from helping prevent crises in the first place, closer monitoring of the fundamentals of countries and reporting to the public can help lower the risk of a surprise crisis in one country resulting in harmful spillovers to other countries. 


\section{APPENDIX}

\section{A. Proofs of Propositions}

Before stating the proofs for the propositions, we first derive the equilibrium price function, equation (3).

Since the supply of assets is uncertain and unobserved, the price realization serves as a signal that, conditional on the realization of the fundamentals, is normally distributed (since $S_{c}$ is normal) with precision $\alpha_{P}$. Therefore, the conditional distribution function of $\theta_{c}$ given $P_{c}$ and $x_{j, i}$ will also be normal with

$$
\begin{aligned}
& E\left(\theta_{c} \mid x_{j, i}, P_{c}\right)=\frac{\hat{\alpha}_{j}}{\alpha_{P}+\hat{\alpha}_{j}} x_{j, i}+\frac{\alpha_{P}}{\alpha_{P}+\hat{\alpha}_{j}} P_{c} \\
& V\left(\theta_{c} \mid x_{j, i}, P_{c}\right)=\frac{1}{\alpha_{P}+\hat{\alpha}_{j}}
\end{aligned}
$$

where, once again, $j \quad\{I, U\}$. We can then rewrite the expected utility of the investor as

$$
\begin{aligned}
E\left(-e^{-\gamma W_{i}}\right) & =E\left(-e^{-\gamma\left(W_{0, i}-P_{c} k_{j, i}+\theta_{c} k_{j, i}\right)}\right) \\
& =-\gamma\left(W_{0, i}-P_{c} k_{j, i}+k_{j, i}\left(\frac{\hat{\alpha}_{j}}{\alpha_{P}+\hat{\alpha}_{j}} x_{j, i}+\frac{\alpha_{P}}{\alpha_{P}+\hat{\alpha}_{j}} P_{c}\right)-\frac{\gamma}{2} k_{j, i}^{2}\left(\frac{1}{\alpha_{P}+\hat{\alpha}_{j}}\right)\right)
\end{aligned}
$$

using the properties of the lognormal distribution.

The first-order condition of the problem is then

$$
-P_{c}+\frac{\hat{\alpha}_{j}}{\alpha_{P}+\hat{\alpha}_{j}} x_{j, i}+\frac{\alpha_{P}}{\alpha_{P}+\hat{\alpha}_{j}} P_{c}=\gamma k_{j, i}\left(\frac{1}{\alpha_{P}+\hat{\alpha}_{j}}\right)
$$

from which we get the demand function for the investor:

$$
k_{j, i}=\frac{\hat{\alpha}_{j}}{\gamma}\left(x_{j, i}-P_{c}\right)
$$

Given that there are $\lambda$ informed investors and $(1-\lambda)$ uninformed investors and that $\mathrm{E}\left(x_{j, i} \mid \theta_{c}\right)=$ $\theta_{c}$, we have the following market clearing condition:

$$
\frac{\lambda \hat{a}_{I}}{\gamma}\left(\theta_{c}-P_{c}\right)+\frac{1-\lambda}{\gamma}\left(\theta_{c}-P_{c}\right)=S_{c}
$$


which gives us the equilibrium price function:

$$
P_{c}=\theta_{c}-\frac{\gamma}{\lambda \hat{\alpha}_{I}+(1-\lambda)} S_{c}
$$

We now present proofs of the propositions:

Proposition 1: For a given realization of a positive liquidity shock, there exists a threshold value of fundamentals, $\theta_{c}^{*}\left(\gamma, S_{c}, \hat{a}_{I}\right)>0$, implicitly defined by

$$
R\left(\theta_{c}^{*}\right) P_{c}\left(\theta_{c}^{*}, S_{c}\right)=\theta_{c}^{*}
$$

such that the firm will choose to discontinue its project if $\theta_{c}<\theta_{c}^{*}\left(\gamma, S_{c}, \hat{a}_{I}\right)$.

\section{Proof:}

In the event of a liquidity shock, the firm will only continue the project if $R(\theta) P(\theta, S)>\theta$. From equation (3), we can rewrite this condition as

$$
R(\theta)\left[\theta-\frac{\gamma}{\lambda \hat{\alpha}_{I}+(1-\lambda)} S\right]>\theta
$$

At $\theta<0$, we know that $R<0$ and so the project will be discontinued since the return on the project is lower than the risk-free return. At $\theta=0$, we have equation (10) holding at equality since $R(0)=0$.

The slope of the left hand side of the inequality is given by

$$
\frac{\partial}{\partial \theta}[R(\theta) P(\theta, S)]=R^{\prime}(\theta)\left[\theta-\frac{\gamma}{\lambda \hat{\alpha}_{I}+(1-\lambda)} S\right]+R(\theta)
$$

At $\theta=0$, the slope is $-\frac{\gamma}{\lambda \hat{\alpha}_{I}+(1-\lambda)} S R^{\prime}(0)<0$. Therefore, the left-hand-side of equation (10) is decreasing at $\theta=0$ while the right-hand-side is increasing. The second derivative of the function, however, is given by

$$
\frac{\partial^{2}}{\partial \theta^{2}}[R(\theta) P(\theta, S)]=R^{\prime \prime}(\theta)\left[\theta-\frac{\gamma}{\lambda \hat{\alpha}_{I}+(1-\lambda)} S\right]+2 R^{\prime}(\theta)
$$

which is positive as $\theta$ increases. The graph defined by the left-hand-side of the inequality will, therefore, intersect with the graph defined by the right-hand-side at some value of $\theta, \theta^{*}$ $>0$ implicitly defined by 


$$
R\left(\theta^{*}\right) P\left(\theta^{*}, S\right)=\theta^{*}
$$

Since the left-hand-side of the inequality is increasing with $\$ \theta \$$ at this point, we have that $R(\theta)\left[\theta-\frac{\gamma}{\lambda \hat{\alpha}_{I}+(1-\lambda)} S\right]>\theta$ for $\theta>\theta^{*}$.

Corollary 1: Based on the equation that defines $\theta_{c}^{*}$, equation (5), we have that the threshold value for fundamentals

(i) increases if investors are more risk-averse, $\frac{\partial \theta_{c}^{*}}{\partial \gamma}>0$.

(ii) is higher for higher realizations of the liquidity shock, $\frac{\partial \theta_{c}^{*}}{\partial S_{c}}>0$.

(iii) is lower for higher beliefs on the precision of the information-gathering technology, $\frac{\partial \theta_{c}^{*}}{\partial \hat{\alpha}_{I}}<0$.

(iv) is lower for a higher proportion of informed investors, $\frac{\partial \theta_{c}^{*}}{\partial \lambda}<0$.

\section{Proof:}

The results in the Corollary are obtained through the use of the Implicit Function Theorem on equation (5). We show the derivation for result $(i)$ while the other three results can be derived in an analogous manner. The partial derivative of $\theta^{*}$ with respect to the coefficient of absolute risk aversion, $\gamma$ is given by

$$
\frac{\partial \theta^{*}}{\partial \gamma}=\frac{\frac{S}{\lambda \hat{\alpha}_{I}+(1-\lambda)} R\left(\theta^{*}\right)}{R^{\prime}\left(\theta^{*}\right)\left[\theta^{*}-\frac{\gamma}{\lambda \hat{\alpha}_{I}+(1-\lambda)} S\right]+R\left(\theta^{*}\right)-1}
$$

The numerator of the fraction on the right-hand-side is unambiguously positive. The overall sign of the derivative, therefore, depends on the sign of the denominator. The denominator, however, can be shown to be positive. From the proof for Proposition 1, we saw that the graph defined by $R(\theta) P(\theta, S)$ intersects the 45 -degree line from below at $\theta=\theta^{*}$. Therefore, the slope of that graph, which is $R^{\prime}\left(\theta^{*}\right)\left[\theta^{*}-\frac{\gamma}{\lambda \hat{\alpha}_{I}+(1-\lambda)} S\right]+R\left(\theta^{*}\right)$ is greater than 1 , which makes the denominator positive. The proofs for the other two results proceed in a similar fashion. 
Proposition 2: The share of informed investors, $\lambda$, in equilibrium will be as follows:

$$
\begin{aligned}
& \lambda=0 \text { if } c>b \\
& \lambda=1 \text { if } c<a ; \text { and } \\
& \lambda \quad(0,1) \text { if } c \quad[a, b] .
\end{aligned}
$$

where $a=\frac{1}{2 \gamma} \ln \left(\frac{\hat{\alpha}_{I}\left(\gamma^{2}+\hat{\alpha}_{I}\right)}{\gamma^{2}+\hat{\alpha}_{I}^{2}}\right)$ and $b=\frac{1}{2 \gamma} \ln \left(\hat{\alpha}_{I}\right)$.

\section{Proof:}

We first have to find $E U_{I}$ and $E U_{U}$ where the expectation is taken prior to the realization of any uncertainty.

$$
\begin{aligned}
E U_{I} & =E\left[-\exp \left(-\gamma\left(W_{0}-c \dashv(\theta-P) k_{I}\right)\right)\right] \\
& =E\left[-\exp \left(-\gamma\left(W_{0}-c+\left(\frac{\gamma}{\lambda \hat{\alpha}_{I}+(1-\lambda)} S\right) \frac{\hat{\alpha}_{I}}{\gamma}\left(\varepsilon_{I, i}+\frac{\gamma}{\lambda \hat{\alpha}_{I}+(1-\lambda)} S\right)\right)\right)\right]
\end{aligned}
$$

where we have left out the subscripts denoting country $c$ and investor $i$.

Let $a_{1}=W_{0}-c ; a_{2}=\frac{\gamma}{\lambda \hat{\alpha}_{I}+(1-\lambda)}$ and $a_{3}=\frac{\hat{\alpha}_{I}}{\gamma}$.

We then have

$$
E U_{I}=E\left\{-\exp \left(-\gamma\left(a_{1} \dashv a_{2} a_{3} S\left(\varepsilon_{I, i} \dashv a_{2} S\right)\right)\right)\right\}
$$

By the independence assumption made earlier, the vector $\left(S, \varepsilon_{I}\right)$ has a bivariate normal distribution with mean $(0,0)$ and covariance matrix

$$
M=\left(\begin{array}{cc}
1 & 0 \\
0 & 1 / \hat{\alpha}_{I}
\end{array}\right)
$$

The joint density function is

$$
\frac{1}{2 \pi \sigma_{I}} \exp \left(-\frac{1}{2}\left(S^{2}+\hat{\alpha}_{I} \varepsilon_{I}^{2}\right)\right)
$$

We can then write equation (14) as

$$
-\int_{S} \int_{\varepsilon} \frac{1}{2 \pi \sigma_{I}} \exp \left(-\frac{1}{2} S^{2}-\frac{1}{2} \hat{\alpha}_{I} \varepsilon_{I}^{2}-\gamma\left(a_{1}+a_{2} a_{3} S \varepsilon_{I}+a_{2}^{2} a_{3} S^{2}\right)\right) d \varepsilon d S
$$


Let $a_{4}=\frac{1}{2}+\gamma a_{2}^{2} a_{3} ; a_{5}=\frac{1}{2} \hat{\alpha}_{I} ; a_{6}=\gamma a_{2} a_{3}$ and $a_{7}=\gamma a_{1}$.

We then have

$$
\begin{aligned}
& -\int_{S} \int_{\varepsilon} \frac{1}{2 \pi \sigma_{I}} \exp \left(-\left(a_{4} S^{2}+a_{5} \varepsilon_{I}^{2}+a_{6} S \varepsilon_{I}+a_{7}\right)\right) d \varepsilon d S \\
& \quad=-\int_{S} \frac{1}{2 \pi \sigma_{I}} \sqrt{\frac{\pi}{a_{5}}} \exp \left(\frac{a_{6}^{2} S^{2}-4 a_{5}\left(a_{7}+a_{4} S^{2}\right)}{4 a_{5}}\right) d S \\
& =-\int_{S} \frac{1}{\sqrt{2 \pi}} \exp \left(-\left(\left(\frac{4 a_{5} a_{4}-a_{6}^{2}}{4 a_{5}}\right) S^{2}+a_{7}\right)\right) d S \\
& =-\exp \left(-a_{7}\right) \frac{1}{\sqrt{2 \pi}}\left(\frac{4 a_{5}}{4 a_{5} a_{4}-a_{6}^{2}}\right)^{1 / 2} \sqrt{\pi} \\
& =-\exp \left(-\gamma\left(W_{0}-c\right)\right)\left(\frac{1}{1+\hat{\alpha}_{I} \phi^{2}}\right)^{1 / 2}
\end{aligned}
$$

where $\phi=\left(\frac{\gamma}{\lambda \hat{\alpha}_{I}+(1-\lambda)}\right)$.

We can find $E U_{U}$ in an analogous manner. With the results above, we have $\lambda=1$ if $E U_{I}>$ $E U_{U}$, or

$$
\begin{aligned}
-\exp \left(-\gamma\left(W_{0}-c\right)\right)\left(\frac{1}{1+\hat{\alpha}_{I} \phi^{2}}\right)^{1 / 2} & >-\exp \left(-\gamma W_{0}\right)\left(\frac{1}{1+\phi^{2}}\right)^{1 / 2} \\
e^{2 \varkappa}\left(1+\phi^{2}\right) & <1+\hat{\alpha}_{I} \phi^{2} \\
e^{2 \gamma} & <\frac{\hat{\alpha}_{I}\left(\gamma^{2}+\hat{\alpha}_{I}\right)}{\left(\gamma^{2}+\hat{\alpha}_{I}^{2}\right)} \\
c & <\frac{1}{2 \gamma} \ln \left(\frac{\hat{\alpha}_{I}\left(\gamma^{2}+\hat{\alpha}_{I}\right)}{\left(\gamma^{2}+\hat{\alpha}_{I}^{2}\right)}\right)
\end{aligned}
$$

Analogously, we have $\lambda=0$ if $E U_{I}<E U_{U}$, or

$$
\begin{aligned}
-\exp \left(-\gamma\left(W_{0}-c\right)\right)\left(\frac{1}{1+\hat{\alpha}_{I} \phi^{2}}\right)^{1 / 2} & <-\exp \left(-\gamma W_{0}\right)\left(\frac{1}{1+\phi^{2}}\right)^{1 / 2} \\
e^{2 \gamma} & >\hat{\alpha}_{I} \\
c & >\frac{1}{2 \gamma} \ln \left(\hat{\alpha}_{I}\right)
\end{aligned}
$$


We will, therefore, have an interior value for $\lambda \quad(0,1)$ when

$$
c \in\left[\frac{1}{2 \gamma} \ln \left(\frac{\hat{\alpha}_{I}\left(\gamma^{2}+\hat{\alpha}_{I}\right)}{\left(\gamma^{2}+\hat{\alpha}_{I}^{2}\right)}\right) \frac{1}{2 \gamma} \ln \left(\hat{\alpha}_{I}\right)\right]
$$

Corollary 2: Let the cost of acquiring information-gathering technology be such that we have an interior solution for $\lambda$. We then have that the fraction of informed investors increases for higher beliefs of the precision of the information-gathering technology, $\frac{\partial \lambda}{\partial \hat{\alpha}_{I}}>0$, for beliefs $\hat{a}_{I}$ that are not too large.

\section{Proof:}

For interior solutions, the share of informed investors is given by

$$
\lambda=\frac{1}{\hat{\alpha}_{I}-1}\left[\gamma \sqrt{\frac{\hat{\alpha}_{I}-e^{2 \varkappa}}{e^{2 \varkappa}-1}-1}\right]
$$

We then have that

$$
\frac{\partial \lambda}{\partial \hat{\alpha}_{I}}=\frac{1}{\hat{\alpha}_{I}-1}\left[\frac{\gamma}{2}\left(\hat{\alpha}_{I}-e^{2 x}\right)^{-1 / 2}\left(e^{2 x}-1\right)^{-1 / 2}\right]-\frac{1}{\left(\hat{\alpha}_{I}-1\right)^{2}}\left[\gamma \sqrt{\frac{\hat{\alpha}_{I}-e^{2 \gamma}}{e^{2 x}-1}-1}\right]
$$

The share of informed investors will increase with higher beliefs on the precision of the information-gathering technology if

$$
\gamma e^{2 x}+\left[\left(\hat{\alpha}_{I}-e^{2 x}\right)\left(e^{2 x}-1\right)\right]^{1 / 2}>\frac{\gamma\left(\hat{\alpha}_{I}+1\right)}{2}
$$

For interior solutions of $\lambda$, we know that $c \quad[a, b]$ where $a=\frac{1}{2 \gamma} \ln \left(\frac{\hat{\alpha}_{I}\left(\gamma^{2}+\hat{\alpha}_{I}\right)}{\left(\gamma^{2}+\hat{\alpha}_{I}^{2}\right)}\right)$ and $b=\frac{1}{2 \gamma} \ln \left(\hat{\alpha}_{I}\right)$. At one extreme point, $c=b$, we can easily show that the inequality (16) holds. At the other extreme, $c=a$, we can rewrite inequality (16) as

$$
\frac{\gamma \hat{\alpha}_{I}\left(\gamma^{2}+\hat{\alpha}_{I}\right)}{\left(\gamma^{2}+\hat{\alpha}_{I}^{2}\right)}+\left[\left(\frac{\hat{\alpha}_{I}\left(\gamma^{2}+\hat{\alpha}_{I}\right)}{\left(\gamma^{2}+\hat{\alpha}_{I}^{2}\right)}-1\right)\left(\hat{\alpha}_{I}-\frac{\hat{\alpha}_{I}\left(\gamma^{2}+\hat{\alpha}_{I}\right)}{\left(\gamma^{2}+\hat{\alpha}_{I}^{2}\right)}\right)\right]^{1 / 2}>\frac{\gamma\left(\hat{\alpha}_{I}+1\right)}{2}
$$




$$
\Rightarrow \hat{\alpha}_{I}^{3}-3 \hat{\alpha}_{I}^{2}+\left(2-3 \gamma^{2}\right) \hat{\alpha}_{I}+\gamma^{3}<0
$$

which holds as long as $\hat{a}_{I}$ is not too large. 


\section{B. Additional Tables}

Table 5: Sample of Countries

Developed Countries Emerging Market Countries

\begin{tabular}{lllll}
\hline \multirow{2}{*}{ Asia \& Australia } & Western Europe \& & Asia \& Australia & Eastern Europe & Latin America \\
& North America & & Chech Republic & Argentina \\
\hline \multirow{2}{*}{ Australia } & Canada & China & Hungary & Brazil \\
Hong Kong & France & India & Poland & Chile \\
Japan & Germany & Indonesia & Romania & Colombia \\
New Zealand & Italy & Korea & Russia & Mexico \\
& Netherlands & Malaysia & Slovakia & Peru \\
& Norway & Singapore & Turkey & Venezuela \\
& Spain & Taiwan & Ukraine & \\
& Sweden & Thailand & & \\
& Switzerland & & & \\
& UK & & & \\
& USA & & & \\
\end{tabular}




\section{Table 6: List of Variables}

Variables

Crisis measure:

Significant drop in stock market returns

\section{Measures}

Basis for the crisis measure is the percentage change in US \$ national, total return, stock market indices relative to the previous month. A month is counted as a crisis month if the total return drops at least 2 standard deviations below the sample mean. Subsequent months are also counted as crisis months until returns move back into the one standard deviation band around the sample mean.

\section{Explanatory Variables:}

Uncertainty measure

Mean growth expectations

Stock market volatility

Changes in political risk

Changes in economic risk

Changes in financial risk

Interest rate in financial center
Monthly data of the weighted average of the standard deviations of the current and following year forecast of GDP growth across survey respondents. In January, the standard deviation of the current year forecast is given a weight of $11 / 12$ while the standard deviation of the following year forecasts is given a weight of 1/12. In February, the current year forecast receives a weight of 10/12 while the follwing year forecast is weighted by $2 / 12$. This scheme continues until December where a weighting of $0 / 12$ is given for the current year forecast and $12 / 12$ for the following year forecast.

Monthly data of the weighted average of the mean forecast by survey respondents of the current and following year GDP growth. The weighting scheme is the same as for the standard deviation.

Standard deviation of daily returns calculated using a rolling window of three months.

Monthly change in the political risk indicator.

Monthly change in the economic risk indicator.

Monthly change in the financial risk indicator.

Monthly average of 10 year US government bond yield

\section{Sources}

2 sets of crisis measures: 1) IFC investable, total return indices, 2) MSCI total return indices. For both cases, we have to use local sources for Romania, Slovakia and Romania. To convert returns from these three national indices into US dollars, we use end of period data on exchange rates from the IMF's International Financial Statistics (IFS).

Consensus Economics

Consensus Economics

Same as crisis measure.

However, restricted availability of daily returns.

ICRG

ICRG

ICRG

BLOOMBERG - GT10 GOVT 
Variables

Alternative contagion channels: Index of common creditors

Trade share

Index of common overexposed fund investors

Stock market size

\section{Measures}

Measures the degree of dependence on the same creditors as the initial crisis country. The index is computed as the sum over all creditors of the product of the dependence of country $B$ on creditor $i$ and the importance of the initial crisis country, $A$, for creditor $i$. The dependence of country $B$ on creditor $i$ is the ratio of the volume that country $B$ borrows from creditor $i$ relative to the total borrowing by country $B$. The importance of country $A$ to creditor $i$ is the ratio of the volume that creditor $i$ lends to country $A$ relative to total lending by creditor $i$.

Exports from country $B$ to the initial crisis country relative to Country B's total exports.

Degree of dependence on fund investors that are overexposed to the initial crisis country

Market value of IFC investable / FTSE index

\section{Sources}

BIS Quarterly Review, consolidated banking data, Table 9B. We construct monthly timeseries from the quarterly observations by interpolation.

IMF: Direction of trade statistics

Broner, Gelos, Reinhart (2006)

IFC investable/ FTSE index 


\section{Table 7: Step 2 - Effect of Uncertainty on the Probability of a Crisis, Restricting Attention to the Mexican, Russian and Thai Crises}

Discrete dependent variable regressions of crises in potentially affected countries on the lagged uncertainty there Step 2, Effect of uncertainty in potentially affected countries, B, on the occurrence of crises there. A dummy of stock market crises is the dependent variable. Countries A are excluded from the group of other countries, B.

(3)

(4)

(5)

(6)

pooled probit, pooled logit, linear probability,

\begin{tabular}{|c|c|c|c|c|c|c|}
\hline & $\begin{array}{c}\text { pooled probit, } \\
\text { all crises, all } \\
\text { countries }\end{array}$ & $\begin{array}{l}\text { pooled probit, } \\
\text { all crises, } \\
\text { emerging } \\
\text { markets }\end{array}$ & $\begin{array}{l}\text { pooled logit, } \\
\text { all crises, all } \\
\text { countries }\end{array}$ & $\begin{array}{l}\text { pooled logit, } \\
\text { all crises, } \\
\text { emerging } \\
\text { markets }\end{array}$ & $\begin{array}{c}\text { linear } \\
\text { probability, } \\
\text { all crises, all } \\
\text { countries }\end{array}$ & $\begin{array}{c}\text { probability, } \\
\text { all crises, } \\
\text { emerging } \\
\text { markets }\end{array}$ \\
\hline \multirow{2}{*}{$\begin{array}{l}\text { lag of interaction of uncert. in B \& } \\
\text { crises in Mex, Rus, Tha }\end{array}$} & $0.339 * * *$ & $0.344 * * * *$ & $0.605 * * *$ & 0.630 **** & $0.109 * * *$ & $0.086 * * *$ \\
\hline & $(0.077)$ & $(0.081)$ & $(0.155)$ & $(0.163)$ & $(0.008)$ & $(0.012)$ \\
\hline \multirow{2}{*}{$\begin{array}{l}\text { lag of interact. com creditors \& } \\
\text { crisis in A }\end{array}$} & $11.347 * * *$ & $12.472^{* * *}$ & $22.844 * * *$ & $24.820^{* * * *}$ & $0.165 * *$ & $2.610^{* * *}$ \\
\hline & $(2.801)$ & $(3.146)$ & $(5.506)$ & $(5.884)$ & $(0.062)$ & $(0.483)$ \\
\hline \multirow{2}{*}{ lag of interact. tradeshare \& crisis in } & $5.323^{* *}$ & $5.250 * *$ & $10.452 * *$ & $10.283^{*} *$ & $1.172 * * *$ & $0.954 * * *$ \\
\hline & $(2.243)$ & $(2.299)$ & $(4.368)$ & $(4.458)$ & $(0.207)$ & $(0.313)$ \\
\hline \multirow{2}{*}{$\begin{array}{l}\text { lag of interact. market size \& crisis } \\
\text { in } A\end{array}$} & -0.000 & -0.000 & -0.000 & $-0.000 *$ & -0.000 & $-0.000^{* *}$ \\
\hline & $(0.000)$ & $(0.000)$ & $(0.000)$ & $(0.000)$ & $(0.000)$ & $(0.000)$ \\
\hline \multirow{2}{*}{ lag of mean growth expectation } & 0.031 & 0.018 & 0.079 & 0.057 & 0.003 & 0.003 \\
\hline & $(0.030)$ & $(0.032)$ & $(0.062)$ & $(0.065)$ & $(0.003)$ & $(0.004)$ \\
\hline \multirow{2}{*}{ lag of stockmarket volatiltiy } & 0.602 & 0.482 & 1.104 & 0.887 & 0.062 & 0.039 \\
\hline & $(0.811)$ & $(0.865)$ & $(1.390)$ & $(1.499)$ & $(0.089)$ & $(0.116)$ \\
\hline \multirow{2}{*}{ lag of 10 year US gov bond rate } & $29.052 * * *$ & $31.562 * * *$ & $55.753 * * *$ & $56.279 * * *$ & 0.570 & $2.092 * *$ \\
\hline & $(7.376)$ & $(8.287)$ & $(14.758)$ & $(16.010)$ & $(0.434)$ & $(0.818)$ \\
\hline country effects & yes & yes & yes & yes & yes & yes \\
\hline \multirow[t]{2}{*}{ Constant } & $-4.336^{* * *}$ & $-4.409 * * *$ & $-8.421 * * *$ & $-8.321 * * *$ & -0.043 & $-0.140 * * *$ \\
\hline & $(0.540)$ & $(0.582)$ & (1.103) & $(1.154)$ & $(0.030)$ & $(0.050)$ \\
\hline Observations & 1983 & 1280 & 1983 & 1280 & 2989 & 1474 \\
\hline \multicolumn{5}{|c|}{ F } & 0.22 & 0.25 \\
\hline \multicolumn{7}{|c|}{ Standard errors in parentheses, $*$ significant at $10 \% ; * *$ significant at $5 \% ; * * *$ significant at $1 \%$} \\
\hline
\end{tabular}




\section{Table 8: Step 2 - Effect of Uncertainty on the Probability of a Crisis, Additional Control for Common Overexposed Fund Investors}

Discrete dependent variable regressions of crises in potentially affected countries on the lagged uncertainty there Step 2, Effect of uncertainty in potentially affected countries, B, on the occurrence of crises there. A dummy of stock market crises is the dependent variable. Countries A are excluded from the group of other countries, B.

(3)

(4)

(5)

(6)

\begin{tabular}{|c|c|c|c|c|c|c|}
\hline & $\begin{array}{l}\text { pooled probit, } \\
\text { all crises, all } \\
\text { countries }\end{array}$ & $\begin{array}{c}\text { pooled probit, } \\
\text { all crises, } \\
\text { emerging } \\
\text { markets }\end{array}$ & $\begin{array}{l}\text { pooled logit, } \\
\text { all crises, all } \\
\text { countries }\end{array}$ & $\begin{array}{l}\text { pooled logit, } \\
\text { all crises, } \\
\text { emerging } \\
\text { markets }\end{array}$ & $\begin{array}{c}\text { linear } \\
\text { probability, all } \\
\text { crises, all } \\
\text { countries }\end{array}$ & $\begin{array}{c}\text { linear } \\
\text { probability, all } \\
\text { crises, } \\
\text { emerging } \\
\text { markets }\end{array}$ \\
\hline $\begin{array}{l}\text { lag of interaction of uncert. in B \& } \\
\text { crises in Mex, Rus, Tha }\end{array}$ & $\begin{array}{c}0.333 * * * \\
(0.088)\end{array}$ & $\begin{array}{l}0.380 * * * \\
(0.092)\end{array}$ & $\begin{array}{l}0.634 * * * \\
(0.167)\end{array}$ & $\begin{array}{l}0.739 * * * \\
(0.178)\end{array}$ & $\begin{array}{l}0.074 * * * \\
(0.018)\end{array}$ & $\begin{array}{c}0.088 * * * \\
(0.018)\end{array}$ \\
\hline $\begin{array}{l}\text { lag of interact. com creditors \& } \\
\text { crisis in A }\end{array}$ & $\begin{array}{c}2.069 \\
(4.016)\end{array}$ & $\begin{array}{c}2.612 \\
(4.108)\end{array}$ & $\begin{array}{l}3.219 \\
(7.215)\end{array}$ & $\begin{array}{l}4.100 \\
(7.425)\end{array}$ & $\begin{array}{c}0.747 \\
(0.850)\end{array}$ & $\begin{array}{l}1.021 \\
(0.862)\end{array}$ \\
\hline $\begin{array}{l}\text { lag of interact. tradeshare \& crisis } \\
\text { in A }\end{array}$ & $\begin{array}{l}5.108 \\
(5.042)\end{array}$ & $\begin{array}{c}5.047 \\
(5.069)\end{array}$ & $\begin{array}{l}9.393 \\
(9.025)\end{array}$ & $\begin{array}{l}9.100 \\
(9.046)\end{array}$ & $\begin{array}{c}0.887 \\
(1.050)\end{array}$ & $\begin{array}{c}0.875 \\
(1.047)\end{array}$ \\
\hline $\begin{array}{l}\text { lag of interact. market size \& crisis } \\
\text { in A }\end{array}$ & $\begin{array}{l}-0.000 \\
(0.000)\end{array}$ & $\begin{array}{l}-0.000 \\
(0.000)\end{array}$ & $\begin{array}{l}-0.000 \\
(0.000)\end{array}$ & $\begin{array}{l}-0.000 \\
(0.000)\end{array}$ & $\begin{array}{l}-0.000 \\
(0.000)\end{array}$ & $\begin{array}{l}-0.000 \\
(0.000)\end{array}$ \\
\hline $\begin{array}{l}\text { lag of interact. overexp. index \& } \\
\text { crisis in A }\end{array}$ & $\begin{array}{l}0.012 * * \\
(0.005)\end{array}$ & $\begin{array}{l}0.012^{* *} \\
(0.005)\end{array}$ & $\begin{array}{l}0.021^{* *} \\
(0.009)\end{array}$ & $\begin{array}{l}0.021 * * \\
(0.009)\end{array}$ & $\begin{array}{c}0.001 \\
(0.001)\end{array}$ & $\begin{array}{c}0.001 \\
(0.001)\end{array}$ \\
\hline lag of mean growth expectation & $\begin{array}{c}0.228^{* * *} \\
(0.046)\end{array}$ & $\begin{array}{c}0.222 * * * \\
(0.048)\end{array}$ & $\begin{array}{c}0.433^{* * *} \\
(0.088)\end{array}$ & $\begin{array}{c}0.428 * * * \\
(0.092)\end{array}$ & $\begin{array}{c}0.040 * * * \\
(0.008)\end{array}$ & $\begin{array}{c}0.038 * * * \\
(0.009)\end{array}$ \\
\hline lag of stockmarket volatiltiy & $\begin{array}{c}16.420 * * * \\
(6.036)\end{array}$ & $\begin{array}{c}13.481^{* *} \\
(6.258)\end{array}$ & $\begin{array}{c}30.134 * * * \\
(11.081)\end{array}$ & $\begin{array}{l}24.431 * * \\
(11.571)\end{array}$ & $\begin{array}{c}4.117 * * * \\
(1.213)\end{array}$ & $\begin{array}{c}3.507 * * * \\
(1.243)\end{array}$ \\
\hline lag of 10 year US gov bond rate & $\begin{array}{c}-94.814^{* * * *} \\
(19.283)\end{array}$ & $\begin{array}{c}-101.977 * * * \\
(20.125)\end{array}$ & $\begin{array}{c}-168.811^{* * *} * \\
(35.054)\end{array}$ & $\begin{array}{c}-184.499^{* * *} \\
(36.880)\end{array}$ & $\begin{array}{c}-13.853^{* * * *} \\
(3.329)\end{array}$ & $\begin{array}{c}-14.826^{* * * * *} \\
(3.404)\end{array}$ \\
\hline country effects & yes & yes & yes & yes & yes & yes \\
\hline Constant & $\begin{array}{l}1.971^{*} \\
(1.145)\end{array}$ & $\begin{array}{l}2.434^{* * *} \\
(1.189)\end{array}$ & $\begin{array}{c}3.350 \\
(2.095)\end{array}$ & $\begin{array}{l}4.328^{* *} \\
(2.182)\end{array}$ & $\begin{array}{c}0.575^{* * * *} \\
(0.198)\end{array}$ & $\begin{array}{c}0.644^{* * *} * \\
(0.203)\end{array}$ \\
\hline Observations & 586 & 539 & 586 & 539 & 665 & 618 \\
\hline R-squared & & & & & 0.25 & 0.26 \\
\hline
\end{tabular}




\section{References}

Angeletos, G.-M., and I. Werning (2006), "Crises and Prices: Information Aggregation, Multiplicity, and Volatility,” American Economic Review, 96(5), 1720-1736.

Bannier, C. (2006), "The Role of Information Disclosure and Uncertainty in the 1994/95 Mexican Peso Crisis: Empirical Evidence," Review of International Economics, 14(5), 883-909.

Bem, D. J. (1965), “An Experimental Analysis of Self-Persuasion,” Journal of Experimental Social Psychology, 1, 199-218.

Borensztein, E., and G. Gelos (2003), "A Panic-Prone Pack? The Behavior of Emerging Market Mutual Funds," IMF Staff Papers, 50(1).

Broner, F., G. Gelos, and C. Reinhart (2006), "When in Peril, Retrench: Testing the Portfolio Channel of Contagion," Journal of International Economics, 69(1), 203-230.

Calvo, G., and E. Mendoza (2000), "Rational Contagion and the Globalization of Securities Markets," Journal of International Economics, 51(1), 79-113.

Caramazza, F., L. Ricci, and R. Salgado (2004), "International Financial Contagion in Currency Crises," Journal of International Money and Finance, 23(1), 51-70.

Daniel, K., D. Hirshleifer, and A. Subrahmanyam (1998), "Investor Psychology and Security Market Under- and Overreactions," Journal of Finance, 53(6), 1839-1885.

Diamond, D. W., and R. E. Verrecchia (1981), "Information Aggregation in a Noisy Rational Expectations Economy," Journal of Financial Economics, 9(3), 221-235.

Didier, T., P. Mauro, and S. L. Schmukler (2006), "Vanishing Contagion?,” IMF Policy Discussion Papers 06/01, International Monetary Fund.

Fernandez-Arias, E. (1996), "The New Wave of Private Capital Inflows: Push or Pull?," Journal of Development Economics, 48, 389-418.

Gelos, G., and S. Wei (2005), “Transparency and International Portfolio Holdings,” Journal of Finance, 60(6), 2987-3019.

Gerlach, S., and F. Smets (1996), "Contagious Speculative Attacks," CEPR Discussion Paper, No. 1055.

Glick, R., and A. Rose (1999), "Contagion and Trade: Why are Currency Crises Regional," Journal of International Money and Finance, 18(4), 603-617. 
Goldstein, I., and A. Pauzner (2004), "Contagion of Self-fulfilling Financial Crises Due to Diversification of Investment Portfolios," Journal of Economic Theory, 119(1), 151183.

Goldstein, M. (1998), The Asian Financial Crisis. Washington DC: Institute for International Economics.

Grossman, S. J., and J. E. Stiglitz (1980), "On the Impossibility of Informationally Efficient Markets," American Economic Review, 70(3), 393-408.

Kaminsky, G., and C. Reinhart (2000), "On Crises, Contagion, and Confusion," Journal of International Economics, 51(1), 145-168.

Kaminsky, G., C. Reinhart, and C. Vegh (2003), "The Unholy Trinity of Financial Contagion," The Journal of Economic Perspectives, 17(4), 51-74.

Kodres, L., and M. Pritsker (2002), “A Rational Expectations Model of Financial Contagion," Journal of Finance, 57(2), 769-799.

Mondria, J. (2006), "Financial Contagion and Attention Allocation,” Working Papers 254, University of Toronto, Department of Economics.

Mondria, J., and C. Quintana-Domeque (2007), "Financial Contagion through Attention Reallocation: An Empirical Analysis," Mimeo.

Morris, S., and H. Shin (2003), "Global Games: Theory and Applications (Proceedings of the Eighth World Congress of the Econometric Society)," in Advances in Economics and Econometrics, ed. by M. Dewatripont, L. Hansen, and S. Turnovsky. Cambridge University Press, Cambridge.

Morris, S., and H. S. Shin (2002), "Social Value of Public Information," American Economic Review, 92(5), 1521-1534.

Prati, A., and M. Sbracia (2002), "Currency Crises and Uncertainty About Fundamentals," IMF Working Papers 02/3, International Monetary Fund.

Rigobon, R., and S.-J. Wei (2003), “News, Contagion and Anticipation,” Mimeo.

Tillmann, P. (2004), "Disparate Information and the Probability of Currency Crises: Empirical Evidence," Economics Letters, 84(1), 61-68.

Van Rijckeghem, C., and B. Weder (2001), "Sources of Contagion: Is It Finance or Trade?," Journal of International Economics, 54(2), 293-308. 